\title{
Should Business Groups be Dismantled? The Equilibrium Costs of Efficient Internal Capital Markets*
}

\author{
Heitor Almeida \\ New York University \\ halmeida@stern.nyu.edu \\ Daniel Wolfenzon \\ New York University \\ dwolfenz@stern.nyu.edu
}

(This Draft: July 07, 2004)

\begin{abstract}
We analyze the relationship between conglomerates' internal capital markets and the efficiency of economy-wide capital allocation, and identify a novel cost of conglomeration that arises from an equilibrium framework. Because of financial market imperfections engendered by imperfect investor protection, conglomerates that engage in "winner-picking" (Stein, 1997) find it optimal to allocate scarce capital internally to mediocre projects, even when other firms in the economy have higher productivity projects that are in need of additional capital. This bias for internal capital allocation can decrease allocative efficiency even when conglomerates have efficient internal capital markets, because a substantial presence of conglomerates might make it harder for other firms in the economy to raise capital. We also argue that the negative externality associated with conglomeration is particularly costly for countries that are at intermediary levels of financial development. In such countries, a high degree of conglomeration, generated for example by the control of the corporate sector by family business groups, may decrease the efficiency of the capital market. Our theory generates novel empirical predictions that cannot be derived in models that ignore the equilibrium effects of conglomerates. These predictions are consistent with anecdotal evidence that the presence of business groups in developing countries inhibits the growth of new independent firms due to lack of finance.
\end{abstract}

Key words: capital allocation, conglomerates, investor protection, internal capital markets. JEL classification: G15, G31, D92.

*We wish to thank Yakov Amihud, Murillo Campello, Douglas Diamond, Marty Gruber, Takeo Hoshi, Arvind Krishnamurthy, Holger Mueller, Walter Novaes, Raghuram Rajan, Andrei Shleifer, Jeff Wurgler, Bernie Yeung, and conference participants at Berkeley University Haas School of Business, Stanford Graduate School of Business, University of Maryland, University of North Carolina at Chapel Hill, the Texas Finance Festival 2003, the 2003 Western Finance Association meetings, and the finance workshop at New York University for their comments and suggestions. 


\section{Introduction}

During the 1990s business groups in developing countries, and specially in East Asia, have been under pressure to restructure. Although widely regarded as the engine of economic growth in earlier decades, business groups are now blamed by politicians and commentators for the economic problems (slow growth, financial crises, etc.) affecting some regions of the world. Those against the busting up of business groups contend that these organizations substitute for missing markets (Khanna and Palepu, 1997, 1999). For example, the presence of business groups may improve economic efficiency because their internal capital markets allocate capital among member firms more efficiently than the underdeveloped external capital market does (Hoshi, Kashyap,and Scharfstein, 1991; Khanna and Palepu, 1997; Stein, 1997; Perotti and Gelfer, 2001). In contrast, those in favor of dismantling business groups argue, among other things, that business groups inhibit the growth of small independent firms by depriving these firms of finance. ${ }^{1}$

Existing models of internal capital markets consider conglomerates in isolation, abstracting from the effects that conglomeration might have on other firms in the economy (see Stein, 2003, for a survey of the literature on internal capital markets). ${ }^{2}$ However, the argument that conglomeration makes it harder for small independent firms to raise financing is directly suggestive of such externalities. Is it reasonable to expect that high conglomeration will have negative effects on a country's capital market? If this conjecture is true, it gives rise to important welfare and policy implications. Even if conglomerates' internal capital markets are efficient (in the sense that conglomerates allocate capital to divisions with the highest growth opportunities), one cannot infer that the presence of conglomerates should be encouraged because the benefits of efficient internal capital markets could be outweighed by the negative externalities that conglomerates impose on other firms in the economy. To address these questions, we need an equilibrium model that considers both internal and external capital markets, and the interactions between them. We present such a framework in this paper.

\footnotetext{
${ }^{1}$ See, for example, the article "Small business living with the crumbs" in the The Financial Times of April 23, 1998, for an account of the difficulties that independent firms faced in obtaining finance before the reform of the Korean chaebols.

${ }^{2}$ We use the term conglomerate and business group interchangeably. Although these organizations are different in many respects (for instance a business group is formed by legally independent firms while a conglomerate is typically a single firm with multiple divisions) they both have internal markets that allocate capital among the member firms in the case of business groups (Samphantharak, 2003) and among divisions in the case of conglomerates (Lamont, 1997).
} 
In our model, capital allocation is constrained by the extent of legal protection of outside investors against expropriation by the manager or 'insiders' (La Porta et al. 1997, 1998). When investor protection is low, there is a limit to the fraction of cash flows that entrepreneurs can credibly commit to outside investors (limited pledgeability of cash flows). Because of this friction, the economy has a limited ability to direct capital to its best users: high productivity projects might not be able to pledge a sufficiently high return to attract capital from lower productivity projects.

In this set up, a conglomerate that reallocates capital efficiently (Stein, 1997) allocates the capital of a worthless project to its best unit, even if this unit is of mediocre productivity. A conglomerate prefers this internal reallocation even when there are higher productivity projects in the economy in need of capital, because, due to limited pledgeability, the high productivity projects cannot properly compensate the conglomerate for its capital. In contrast, a stand-alone firm with a worthless project has no internal reallocation options, and thus it finds it optimal to supply the project's capital to the external market. This difference in the reallocation decisions of conglomerates and stand-alones means that a high degree of conglomeration in a country's corporate sector is associated with a smaller supply of capital to high productivity firms and might, under some conditions, decrease the efficiency of aggregate investment.

The model also suggests specific conditions under which conglomerate's internal capital markets increase allocative distortions. For very low levels of investor protection conglomerates actually improve allocative efficiency because the external market works so poorly that high productivity firms cannot raise additional capital irrespective of the amount of capital supplied. Because released capital cannot find its way to high productivity projects, the reallocation of conglomerates to mediocre units is better than no reallocation. For very high investor protection, the conglomerates' internal reallocation bias disappears because high productivity projects can offer a sufficiently high return to attract capital from the conglomerate. In this case, the external market works so well that the allocation of capital becomes independent of the degree of conglomeration. The negative effect of conglomeration on the external capital market is most pronounced for intermediate levels of investor protection. In such circumstances, the legal and contracting environment is good enough to make it possible for the external capital market to work well. However, the external market's residual underdevelopment makes it fragile to the negative externality engendered by conglomeration. In 
other words, for intermediary levels of investor protection the probability that high productivity firms can raise additional capital is very sensitive to capital supply, and thus to the degree of conglomeration. In these cases, the efficiency of capital allocation decreases with conglomeration.

Our theory thus predicts that, in some circumstances, an exogenous decrease in conglomeration can improve the efficiency of capital allocation by increasing the availability of finance to high productivity projects. This prediction is consistent with anecdotal evidence from South Korea. The financing constraints that new independent firms faced in the 1990's were partly attributed to the presence of the chaebols. ${ }^{3}$ It also appears that following the reform of the chaebols, more funds have become available to independent firms. ${ }^{4}$ Korea also appears to be at the intermediate stage of institutional development in which the equilibrium effects of internal capital markets are particularly high. In particular, it is possible that while chaebols played an important role in earlier stages of development of the Korean capital market, it has more recently become a burden as market institutions evolved over time.

Clearly, the degree of conglomeration is not completely exogenous since individual firms have the choice whether to conglomerate. Nevertheless, there is evidence that, in many countries, corporate grouping affiliation is determined to a large extent by history and political pressure (see references in section 4). Thus, we believe that it is meaningful to model exogenous variations in conglomeration. However, we extend the model to allow firms to choose whether to form conglomerates or not. We show that similar results hold when we allow the degree of conglomeration to be endogenously determined. The model has multiple equilibria with high and low levels of conglomeration and, under certain conditions, the equilibrium with high level of conglomeration has worse capital allocation because of the negative externality associated with conglomeration. In addition, we show that despite the negative effects of conglomeration, individual firms have no private incentives to split up if the economy finds itself in the high conglomeration equilibrium. Deconglomeration might have to be centrally mandated, or directly discouraged through policies that increase the cost of conglomeration.

Our results contribute to the literature on whether internal capital markets are efficient (Gertner, Scharfstein and Stein, 1994; Stein, 1997) or not (Shin and Stulz, 1998; Rajan, Servaes and

\footnotetext{
${ }^{3}$ See reference in footnote 1 .

${ }^{4}$ See for example The Economist, April 17 2003, "Unfinished business".
} 
Zingales, 2000; Scharfstein and Stein 2000). We are not the first to point out that conglomerates may have a negative effect on the allocation of capital. Other models also have the implication that, as the financing-related benefits of conglomeration decrease, costs of conglomeration such as less effective monitoring (Stein, 1997), coordination costs (Fluck and Lynch, 1999), free cash-flow (Matsusaka and Nanda, 2002 and Inderst and Mueller, 2003) and incentive problems (Gautier and Heider, 2003) make conglomerates less desirable. However, the literature has focused on conglomerates in isolation and thus has not generated equilibrium implications. ${ }^{5}$ Our paper, by focusing on the interactions between conglomerates' internal capital markets and the efficiency of the external capital market, generates a new theoretical insight as well as novel empirical implications and policy recommendations.

In terms of the theoretical insight, we add to the literature by identifying a novel, equilibrium cost of conglomeration that stems from the negative externality that conglomerates impose on a country's external capital market. This cost implies that conglomerates can be simultaneously detrimental to equilibrium capital allocation, and efficient at allocating capital internally.

In addition, our model generates new testable hypotheses and policy recommendations. For example, we predict that a high degree of conglomeration in a country's corporate sector might increase financing constraints for independent firms that lie outside the conglomerate. We also provide reasons for why the dismantling of conglomerates might need to involve government intervention (see section 6 for a complete list and a discussion of empirical implications and policy recommendations). These implications cannot be generated by models that consider conglomerates in isolation.

Our paper is also related to a recent literature that examines the equilibrium implications of private capital allocation decisions in economies characterized by limited investor protection (Shleifer and Wolfenzon, 2002; Almeida and Wolfenzon 2004; Castro Clementi, MacDonald, 2004) and to an earlier literature that analyzes the relationship between general financing frictions and capital allocation (Levine, 1991; Bencivenga, Smith, and Starr, 1995). However, this literature has not considered the equilibrium effects of conglomerates' internal capital markets, which is the main focus of this paper.

\footnotetext{
${ }^{5}$ Maksimovic and Phillips $(2001,2002)$ are an exception: they analyze allocation decisions by conglomerates in an equilibrium context, but with no role for financial imperfections.
} 
We start in the next section by presenting a very simple example that illustrates the main effect that drives the novel results of our paper. In section 3 we describe our full model, and in section 4 we analyze the relation between the level of conglomeration and the efficiency of capital allocation. The main result of the paper is stated and explained in section 4.4. In section 5, we extend the model to analyze the implications of endogenizing conglomeration. We discuss the empirical and policy implications of the model in section 6, and present our final remarks in section 7. All proofs are in the Appendix.

\section{A simple example}

In this section we present a simple example that illustrates the intuition behind the main results of the full fledged model. The example is designed to highlight the equilibrium cost of internal capital markets that we identify in the simplest possible way. We consider a more general set up starting in section 3 .

Consider an economy with three investment projects, each with a different productivity. An investment of one unit of capital produces a payoff of 5 units if invested in project $H$ (high productivity project), 3 units if invested in project $M$ (medium productivity) and 1 unit if invested in project $L$ (low productivity). There is only one unit of capital to be allocated and this unit happens to be invested in project $L$.

The main friction in this economy is that cash flows cannot be fully pledgeable to outside investors (we discuss this assumption in Section 3.4). We denote by $\lambda$ the fraction that can be pledged to outsiders. Furthermore, in the spirit of Gertner, Scharfstein and Stein (1994) and Stein (1997), we assume that conglomerates' internal capital markets alleviate the limited pledgeability problem that distorts capital allocation in external markets. Specifically, we assume that there is no pledgeability problem for units of capital that are reallocated inside the conglomerate.

We characterize the equilibrium allocation of the unit of capital for two different economies. In the first economy, the three projects are stand-alone firms. In the second economy, projects $L$ and $M$ are part of a two-project conglomerate, while project $H$ is a stand-alone firm. As a benchmark, note that the efficient allocation of capital in both situations is from project $L$ to $H$, generating a total payoff of 5 .

When there are no conglomerates, all capital reallocations must occur through the external 
capital market. Firm $L$ can keep the unit of capital and produce an output of 1 . Alternatively, it can supply this unit to any of the other two firms. Due to limited pledgeability, the maximum firm $M$ can pay is $3 \lambda$, and the maximum firm $H$ can pay is $5 \lambda$. Therefore, conditional on the decision to provide the capital to the market, the stand-alone firm $L$ allocates this capital to project $H$ for a total economy payoff of 5 . However, when pledgeability is low (in particular when $\lambda<\frac{1}{5}$ ) firm $L$ prefers to keep the capital rather than to supply it to the market.

In the second economy, project $L$ (with its unit of capital) is in the conglomerate. The conglomerate can leave the capital in project $L$ and generate 1 or it can choose to reallocate this unit of capital. By allocating internally to project $M$, the conglomerate achieves a payoff of 3 , whereas by allocating to project $H$ through the external capital market, it can achieve a payoff of $5 \lambda$. Thus the conglomerate always reallocates (since $\max \{3,5 \lambda\}>1$ ) but, when $\lambda<\frac{3}{5}$, it reallocates internally to project $M$ instead of externally to project $H$.

It is now easy to see how conglomerates' (efficient) internal capital markets can distort the equilibrium allocation of capital. If $\frac{1}{5} \leq \lambda<\frac{3}{5}$, the economy achieves a total payoff of 5 if there are no conglomerates, but it achieves a payoff of 3 when there is a conglomerate present. Notice that the inefficiency comes about precisely because the conglomerate is performing a privately efficient reallocation of capital. This inefficiency is the novel (equilibrium) cost of internal capital markets that we identify in the paper.

This simple example also shows that the effect of internal capital markets on the equilibrium allocation depends non-monotonically on the pledgeability parameter $\lambda$. If pledgeability is very low $\left(\lambda<\frac{1}{5}\right)$, the conglomerate's internal capital reallocation is socially useful because it increases the total payoff from 1 to 3 . This is a situation in which the external capital market is very poorly developed. The social cost of conglomeration appears at intermediate levels of pledgeability $\left(\frac{1}{5} \leq \lambda<\frac{3}{5}\right)$. For these intermediate levels the external capital market has the potential to work well, but it is sensitive to the presence of conglomerates. The economy would benefit if the conglomerate was dismantled. Finally, for higher levels of pledgeability $\left(\lambda \geq \frac{3}{5}\right)$, the conglomerates' internal reallocation bias disappears since the high productivity project can offer a high return for the unit of capital. In this case, the economy can achieve the efficient allocation of capital irrespective of the level of conglomeration.

A useful way of understanding this result is as follows. A stand-alone firm faces the same 


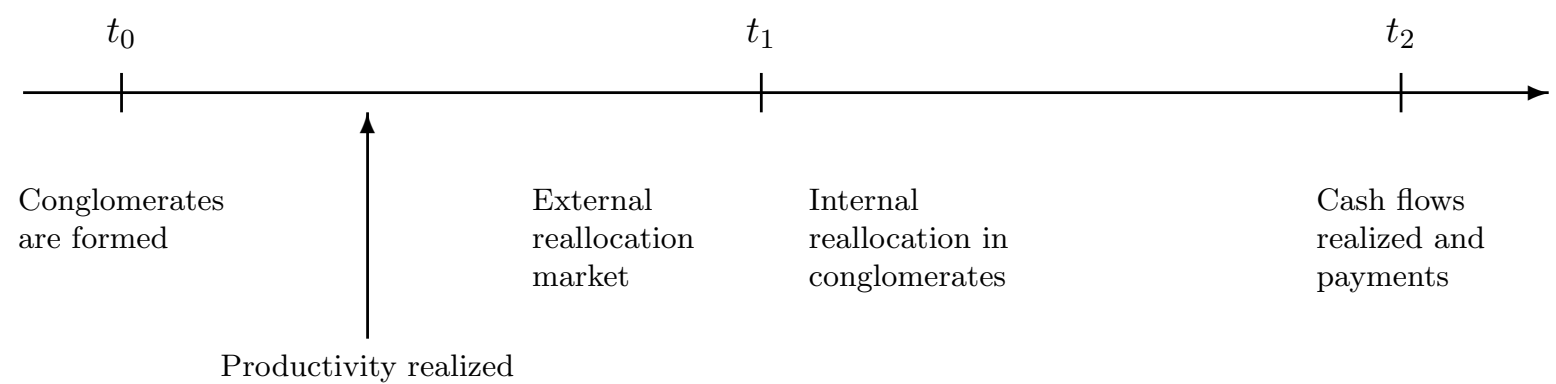

Figure 1: Timing of events

pledgeability problem for all firms in the economy. As a result, conditional on liquidating a project, the stand-alone firm ranks all projects in the socially optimal way (recall the stand-alone firm compares $3 \lambda$ to $5 \lambda$ ). However, the conglomerate faces pledgeability problems only for firms outside the conglomerate (recall the conglomerate compares 3 to $5 \lambda$ ). Thus, a conglomerate has a bias towards internal reallocation. This capital allocation distortion is the cost of conglomeration. The benefit of conglomeration is that, because of capital market imperfections, conglomerates reallocate capital more frequently than stand-alone firms. In sum, conglomerates reallocate capital more frequently but these allocations are not always the socially optimal ones.

As we show in the next few sections, this simple example delivers the same result as our full model. However, this example is artificial in several important dimensions. First, it assumes an extreme scarcity of capital (only one unit needs to be allocated to three competing investment projects). Second, it assumes a particular location for the unit of capital and a particular distribution of productivities in the conglomerate and stand-alone firm (that is, the high productivity project lies outside the conglomerate, in which the entire wealth of the economy is invested). Third, the (re)allocation of capital in the external market is not explicitly modeled. Fourth, the variation in the level of conglomeration is assumed to be exogenous. We tackle these issues in the general model that starts in the next section.

\section{The model}

In this section we develop our full theoretical framework to analyze the effect of conglomeration on the equilibrium allocation of capital.

The timing of events in the model is shown in Figure 1. There are three dates. At date $t_{0}$, 
there is a set $J$ (with measure 1) of entrepreneurs, each with one project (projects are described below) and one unit of capital. ${ }^{6}$ At this date entrepreneurs decide whether to form a conglomerate. The productivity of projects is not known at date $t_{0}$ when conglomerates are formed, however, it becomes public knowledge before date $t_{1}$. In light of the new information, capital can be reallocated among projects at date $t_{1}$. Reallocation can occur in the external capital market or, when projects are in a conglomerate, it can occur internally. We assume that, in addition to the entrepreneurs, there is a group of investors with an aggregate amount of capital $K>1 .^{7}$ Finally, cash flows are realized at date $t_{2}$.

\subsection{Conglomerate formation}

At date $t_{0}$ entrepreneurs form conglomerates. We restrict attention to two-project conglomerates. The intuition holds for conglomerates of any finite number of projects. ${ }^{8}$ We assume that the entrepreneurs that form a conglomerate maximize the conglomerate's total payoff at date $t_{2}$.

After entrepreneurs make their conglomeration decisions, the boundaries of the firms in the economy can be described by a partition $\mathcal{E}$ of $J$, where each element $F \in \mathcal{E}$ is a firm (stand-alone or conglomerate). For example, if project $i \in J$ ends up as a stand-alone firm, then $\{i\} \in \mathcal{E}$, and if projects $j, k \in J$ form a conglomerate then $\{j, k\} \in \mathcal{E}$.

We let $c$ be the fraction of the projects that end up in conglomerates. Thus, there are $c / 2$ conglomerates and $1-c$ stand-alone firms. We refer to $c$ as the degree of conglomeration in the economy.

\section{$3.2 \quad$ Projects and the general technology}

The projects that entrepreneurs have are of infinitesimal size and, at date $t_{0}$, require the unit of capital that entrepreneurs hold. At date $t_{1}$, a project can be liquidated, in which case the entire unit of capital is recovered. If a project is not liquidated, it can receive additional capital or can

\footnotetext{
${ }^{6}$ Because each entrepreneur is associated with one and only one project, we use interchangeably the terms "entrepreneur $j \in J$ " and "project $j \in J$ ".

${ }^{7}$ This capital is in excess of what is needed to fund every project in the economy with two units (the maximum that we will allow in the model, as explained below). Thus, unlike in the simple example of Section 2, there is excess capital in this economy.

${ }^{8}$ Consider our simple example in section 2. If all three firms are inside the same conglomerate, capital is always allocated efficiently irrespective of the location of the high productivity project. Notice, however, that for this result to hold it is crucial that all capital is invested in a single conglomerate.
} 
be continued with no change until date $t_{2}$. At date $t_{2}$, projects generate cash flows. ${ }^{9}$

Projects can have one of three different productivity levels denoted by $L$ (low), $M$ (medium), and $H$ (high). The probability that a project is of productivity $L, M$, and $H$ is $p_{L}, p_{M}$, and $p_{H}$ (with $p_{H}+p_{M}+p_{L}=1$ ), respectively. The probability distribution is independent across projects so that, at date $t_{1}$, exactly a fraction $p_{L}, p_{M}$ and $p_{H}$ of the projects are of type $L, M$ and $H$, respectively. ${ }^{10}$ After the productivity of the projects is realized, there are three different types of stand-alone firms (the $L, M$, and $H$ stand-alone firms) and six different types of conglomerates (the $L L, L M, L H, M M, M H$, and $H H$ conglomerates). We let $t(j) \in\{L, M, H\}$ be the realized productivity of project $j$.

For simplicity, we assume drastic decreasing returns to scale. Depending on its type, a project generates cash flow $Y_{H}, Y_{M}$ or $Y_{L}$ (with $Y_{H}>Y_{M}>Y_{L} \equiv 0$ ) per unit invested, but only for the first two units (i.e., the initial unit with which the project is started at date $t_{0}$ and the unit that is potentially invested at date $\left.t_{1}\right)$. Additional units invested generate no cash flow.

At date $t_{1}$ there is a second technology ('general technology') available to all agents in the economy. We define $x(\omega)$ as the per-unit pay off of the general technology with $\omega$ being the aggregate amount of capital invested in it.

Assumption 1 The general technology satisfies:

a. $\frac{\partial[\omega x(\omega)]}{\partial \omega} \geq 0$

b. $x^{\prime}(\omega) \leq 0$

We assume that total output is increasing in the amount invested in the general technology (assumption 1(a)) but that the per-unit payoff is decreasing (assumption 1(b)). To rank the productivity of the projects and the general technology, we assume that:

\section{Assumption $2 Y_{M}>x(0)$}

The most productive technologies are good projects, followed by medium projects. By assumption 2 , medium projects are more productive than the general technology regardless of the amount invested in the latter $($ since $x(0)>x(\omega)$ by assumption $1(\mathrm{~b})$ ). Finally, the bad projects are the least productive.

\footnotetext{
${ }^{9}$ Because liquidation is costless and there is excess capital, all projects (which are identical ex-ante) will "enter" date $t_{1}$ with one unit of capital invested. This assumption makes the model more symmetric than the simple example of section 2, in which we assumed that only a particular project had capital invested in it.

${ }^{10}$ Notice that any individual project has the same probability of turning out to be $L, M$, or $H$, irrespective of whether it lies in a conglomerate or not (unlike in the simple example of section 2).
} 


\subsection{External capital markets}

At date $t_{1}$, some firms decide to supply their capital to the market, other firms choose to seek capital in the market and others opt out of the market completely. We let $S$ be the set of projects that are liquidated and whose capital is supplied to the external market. That is, if the stand-alone firm $\{i\}$ decides to liquidate and supply its capital to the market then $i \in S$. Similarly, if the conglomerate $\{j, k\}$ decides to supply the capital of unit $j$ to the market then $j \in S$. The total supply of capital to the market is then $K+\int_{\{i \in S\}} d i$, where $K$ is the amount of capital in the hands of other investors.

The rest of the projects are continued until date $t_{2}$. Some firms with continuing projects benefit from raising capital in the market at the prevailing market rate. These firms seek external finance. We let $C$ be the set of projects that form these firms. That is, if conglomerate $\{j, k\}$ seeks two units of capital (one for each project) then $j, k \in C$. Also, some conglomerates prefer to allocate capital internally and neither supply nor demand capital from the external market. We let $O$ be the set of projects that form these conglomerates.

The actions that take place in the external capital market are as follows. First, firms that seek finance announce one contract for each unit of capital they desire to raise. Because projects generate cash out of the first two units of capital, and all projects start with one unit, firms seeking finance announce one contract per continuing project. It will be convenient to label the contracts by the project that ultimately receives the capital rather than by the firm that announces it. For example, we refer to the contract that the stand-alone firm $F=\{i\}$ announces as $P^{i}$. Similarly, a conglomerate $G=\{j, k\}$ seeking two units of capital announces two contracts $P^{j}$ and $P^{k}$.

After firms and conglomerates announce contracts, date- $t_{1}$ investors (investors, stand-alone firms and conglomerates which supply capital to external market) allocate their capital to these contracts and to the general technology so as to maximize the value of their investment. Investors can take any of the contracts offered by any of the firms. An allocation in the capital market can be described by $r^{i}$, the probability that an investor takes contract $P^{i}$, and $\omega^{*}$, the amount allocated to the general technology. ${ }^{11}$

\footnotetext{
${ }^{11}$ We characterize the allocation rule by the probability that a contract is taken because we allow investors to randomize among projects. Of course, after the uncertainty about this randomization is resolved, projects either get capital or they don't. However, we specify the allocation rule by the ex-ante probability of getting capital (rather than the ex-post actual allocation) because this is what matters to firms offering contracts.
} 


\subsection{Limited pledgeability}

The allocation of capital in external markets will be affected by an imperfection at the firm level: firms and conglomerates cannot pledge to outside investors the entire cash flow generated. In particular, we assume that only a fraction $\lambda$ of the returns of the second unit invested is pledgeable. ${ }^{12}$

The limited pledgeability assumption can be justified as being a consequence of poor investor protection, as shown in Shleifer and Wolfenzon (2002). In their model, insiders can expropriate outside investors, but expropriation has costs that limit the optimal amount of expropriation that the insider undertakes. Higher levels of protection of outside investors (i.e., higher costs of expropriation) lead to lower expropriation and consequently higher pledgeability.

Limited pledgeability also arises in other contracting frameworks. For example, it is a consequence of the inalienability of human capital (Hart and Moore 1994). Entrepreneurs cannot contractually commit never to leave the firm. This leaves open the possibility that an entrepreneur could use the threat of withdrawing his human capital to renegotiate the agreed upon payments. If the entrepreneur's human capital is essential to the project, he will get a fraction of the date- $t_{2}$ cash flows. Limited pledgeability is also an implication of the Holmstrom and Tirole (1997) model of moral hazard in project choice. When project choice cannot be specified contractually, investors must leave a high enough fraction of the payoff to entrepreneurs to induce them to choose the project with low private benefits but high potential profitability.

The assumption of limited pledgeability imposes constraints on the amount firms can offer. For example, the offer $P^{i}$ of a stand-alone firm $F=\{i\}$ is constrained by

$$
P^{i} \leq \lambda Y_{t(i)}
$$

The constraints on the contracts $P^{j}$ and $P^{k}$ of a conglomerate $G=\{j, k\}$ with $Y_{t(j)} \leq Y_{t(k)}$ seeking two units of capital depend on the number of units raised. When only one of the two contracts is taken, there are two relevant constraints. The first is a straightforward incentive compatibility constraint, $P^{j} \leq P^{k}$. The conglomerate always allocates the unit raised to its higher productivity project $k$. This condition ensures that the conglomerate's strategy results in capital being allocated to the project for which the contract was intended to. Under this condition, investors

\footnotetext{
${ }^{12}$ The assumption that the cash flows from the first unit are not pledgeable is made only for simplicity. It will become clear that our results do not hinge on this assumption (see footnote 19).
} 
prefer contract $P^{k}$ over $P^{j}$, and will thus take contract $P^{k}$ first.

The second constraint is due to limited pledgeability,

$$
P^{k} \leq \lambda Y_{t(k)}
$$

When the two contracts are taken in equilibrium, the conglomerate allocates one unit to each project and the relevant constraint is

$$
P^{j}+P^{k} \leq \lambda\left(Y_{t(j)}+Y_{t(k)}\right)
$$

\subsection{Internal capital markets}

Once the external capital market closes, we assume that the conglomerate allocates its internal capital to maximize its total payoff. This assumption implies that the conglomerate will seek to reallocate capital towards its most productive projects (as in Stein, 1997). Furthermore, as in the example of Section 2, we assume that there are no pledgeability problems inside a conglomerate, that is, $\lambda=1$ for capital internal capital reallocations. The assumption that internal capital markets alleviate the limited pledgeability problem is in the spirit of the models in Gertner, Scharfstein and Stein (1994), and Stein (1997). Taken together, these two assumptions imply that in our model conglomerates' internal capital markets are privately efficient.

Naturally, we recognize that internal capital markets are not always privately efficient (Stein, 2003). The goal of our assumptions is to highlight the novel cost of internal capital markets that we identify in the paper, which is associated with the effect of internal capital markets on the efficiency of the external capital market. Given our assumptions, in the absence of an externality conglomeration would clearly increase the efficiency of capital allocation.

However, it is important to note that our results do not require internal capital markets to be strictly efficient. First, it is not necessary for $\lambda$ to be strictly equal to one inside a conglomerate. As long as conglomerates' internal capital markets mitigate the limited pledgeability problem that exists in external capital markets, our results will hold. In other words, what is required is that $\lambda$ is higher for capital reallocations that occur inside the conglomerate. Second, and perhaps more importantly, the types of (private) capital allocation distortions that the previous literature has associated with internal capital markets will most likely reinforce our results. Specifically, if conglomerates engage in "socialistic" capital allocation (as suggested for example by Rajan, Servaes, 
and Zingales, 2000), their bias for internal allocation will most likely increase, since conglomerates will be even more reluctant to move capital away from low-productivity units. Given that our results are driven by conglomerates' bias for internal allocation, such considerations would only magnify the externality that we focus on.

\section{Conglomerates and the equilibrium capital allocation}

We start by assuming that the degree of conglomeration in the economy, $c$, is exogenously given. Admittedly, the degree of conglomeration is not completely determined by exogenous factors since individual firms have the choice whether to conglomerate. Still, there are lessons to be learned to the extent that there is some exogenous variation in conglomeration across countries. For example, Khanna and Yafeh (2001, p.9) cite evidence that current corporate grouping affiliation in Japan, South Korea and Eastern Europe is determined to a large extent by history. Hoshi and Kashyap (2001) explain how the pre-war Zaibatsu (family-based business groups) were dissolved by the occupation forces. Moreover, the recent reform of the chaebol in South Korea shows that political pressure is a force that can shape business groups. In any case, we study the implications of endogenizing conglomeration in section 5 .

We solve the model backwards. Since at date $t_{2}$ no decisions are taken, we start by characterizing the internal allocation of funds in a conglomerate.

\subsection{Internal allocation of capital}

After the external capital market has cleared, conglomerates allocate the capital they have to their projects, seeking to maximize the conglomerate's payoff. The allocation rule inside the conglomerate is as follows.

A conglomerate with two continuing projects and two additional units of capital (i.e., two units in addition to the two units the projects started off with) allocates one unit to each project. A conglomerate with two continuing projects and one additional unit of capital allocates this additional unit to its higher productivity project. Finally, a conglomerate with two continuing projects and no additional units of capital transfers the unit of capital from its existing lower productivity project to its higher productivity one. The decision of a conglomerate with a single continuing project is simple since all it can do is to allocate any additional capital to its continuing 
project.

\subsection{Equilibrium of the external capital market}

We describe the equilibrium in the external capital market after the productivity of the projects has been realized. To characterize the equilibrium, we define, for each project $i$, a quantity $\bar{P}^{i}$ in the following way. If project $i$ is in a stand-alone firm then $\bar{P}^{i} \equiv \lambda Y_{t(i)}$. If project $i$ is in a conglomerate with project $j$ then $\bar{P}^{i} \equiv \lambda Y_{t(i)}$ if $Y_{t(i)} \geq Y_{t(j)}$ and $\bar{P}^{i} \equiv \lambda\left(Y_{t(i)}+Y_{t(j)}\right) / 2$ if $Y_{t(i)}<Y_{t(j)}$.

We show in the proof of the next proposition that, with this definition of $\bar{P}^{i}$, we can treat each project $i \in C$ as if it were a stand-alone firm announcing $P^{i}$, with $\bar{P}^{i}$ being the maximum amount this project can offer in the external market. The intuition is as follows. When project $i$ is in a stand-alone firm, the maximum it can offer is simply $\lambda Y_{t(i)}$ (see Equation (1)). If project $i$ is in a conglomerate with project $j$ and $Y_{t(i)} \geq Y_{t(j)}$, the first unit of capital the conglomerate raises is allocated to project $i$. The conglomerate can thus offer up to $\lambda Y_{t(i)}$ for this unit (see Equation (2)). Finally, if project $i$ is in a conglomerate with project $j$ and $Y_{t(i)}<Y_{t(j)}$, it only receives capital when the conglomerate raises two units. The maximum amount per unit that the conglomerate can offer in this case is $\lambda\left(Y_{t(i)}+\lambda Y_{t(j)}\right) / 2$ (see Equation (3)).

Proposition 1 For any allocation of projects to stand-alone firms or conglomerates, $\mathcal{E}$, and any participation decision by firms, sets $S, O$, and $C$, the equilibrium of the external capital market is as follows. All projects with $\bar{P}^{i} \geq R^{*}$ offer $R^{*}$ to investors and projects with $\bar{P}^{i}<R^{*}$ offer any amount strictly less than $R^{*}$. Project $i \in C$ receives capital in the external market

- with certainty, if $\bar{P}^{i}>R^{*}$,

- with probability $r^{*}$, if $\bar{P}^{i}=R^{*}$, and

- with probability 0 , if $\bar{P}^{i}<R^{*}$,

where $R^{*}$ satisfies

$$
x^{-1}\left(R^{*}\right)+\int_{\left\{i \in C \mid \bar{P}^{i}>R^{*}\right\}} d i \leq K+\int_{\{i \in S\}} d i \leq x^{-1}\left(R^{*}\right)+\int_{\left\{i \in C \mid \bar{P}^{i} \geq R^{*}\right\}} d i
$$

and, $r^{*}$ satisfies

$$
x^{-1}\left(R^{*}\right)+\int_{\left\{i \in C \mid \bar{P}^{i}>R^{*}\right\}} d i+\int_{\left\{i \in C \mid \bar{P}^{i}=R^{*}\right\}} r^{*} d i=K+\int_{\{i \in S\}} d i .
$$


The general technology receives $\omega^{*}=x^{-1}\left(R^{*}\right)$ units of capital.

The proof of this proposition, as well as a more detailed description of firms' and investors' strategies, is in the Appendix. The idea of the proof is as follows. Investors allocate capital so as to maximize their return. In equilibrium, investors receive a return of $R^{*}$ on their investment because projects that receive capital offer $R^{*}$, which is also the return of the general technology. Projects that do not receive capital are those that are constrained by pledgeability limits to offer strictly less than $R^{*}$. As a result, no investor can achieve a higher return by switching his capital to an available investment opportunity.

The contracts offered by firms in proposition 1 are optimal given investors' allocation rule. Continuing projects that seek finance (those that form set $C$ ) offer the minimum possible to receive one unit of capital. ${ }^{13}$ Note first that projects that offer strictly less than $R^{*}$ do not receive capital because there are other projects offering this return. Thus, projects that receive capital cannot profitably deviate to a lower offer. Projects that offer strictly more than $R^{*}$ get capital for sure since all other available investment opportunities offer only $R^{*}$. However, in equilibrium, no project offers more than $R^{*}$. First, a project with $\bar{P}>R^{*}$ offers $R^{*}$ and receives capital for sure. This project could potentially offer more than $R^{*}$, but it does not need to do so given the equilibrium allocation rule. And second, a project with $\bar{P}=R^{*}$ receives capital with probability $r^{*}$, which is potentially less than 1 . This project would benefit by raising its offer but cannot do so by limited pledgeability constraints. ${ }^{14}$ Finally, because a project with $\bar{P}<R^{*}$ has to offer strictly less than $R^{*}$, it never gets capital regardless of its offer.

The above explains that, for a given $R$ and $r$, the strategies of the projects and of the investors constitute an equilibrium. The exact values of $R^{*}$ and $r^{*}$ are determined such that the external market clears. Recall that the total supply of capital to the market is $K+\int_{\{i \in S\}} d i$. According to the equilibrium strategies, the total 'demand' for capital by projects and the general technology

\footnotetext{
${ }^{13}$ We can refer to projects offering contracts (rather than stand-alone firms or conglomerates), because we show in the proof of Proposition 1 that we can treat each project $i \in C$ as a stand-alone firm with the constraint that $P^{i} \leq \bar{P}^{i}$.

${ }^{14}$ The fact that projects with $\bar{P}>R^{*}$ receive capital for sure whereas projects with $\bar{P}=R^{*}$ receive capital with some probability (potentially less than 1 ) even though these projects offer the same contract is not an assumption, but rather an implication of equilibrium. As we show in detail in the proof of the proposition, if the allocation rule assigned capital with probability strictly less than one to projects with $\bar{P}>R^{*}$ then an optimal contract would not exist for these projects. Under this rule, projects with $\bar{P}>R^{*}$ would get capital with probability strictly less than one if they offered $R^{*}$, but would get capital for sure if they offered $R^{*}+\epsilon$. The optimal contract would not not exist because $\epsilon$ could always be made smaller.
} 
for a given $R$ and $r$ is $x^{-1}(R)+\int_{\left\{i \in C \mid \bar{P}^{i}>R\right\}} d i+\int_{\left\{i \in C \mid \bar{P}^{i}=R\right\}} r d i$. The first term is the amount of capital allocated to the general technology. The second is the amount of capital allocated to projects with $\bar{P}^{i}>R$, and the third term is the amount of capital allocated to the projects with $\bar{P}^{i}=R$. Equating supply and demand leads to Equation (5). Equation (4) follows directly from Equation (5) by imposing the condition that $r^{*}$ must lie between 0 and 1 .

The equilibrium is illustrated in Figure 2, Panels A and B. The downward sloping curve is the graphical representation of the demand for capital. In Figure 2, we assume that the set $C$ contains all the projects in the stand alone firms $M$ and $H$, and all the projects in conglomerates $M M$, $M H$, and $H H \cdot{ }^{15}$ At high levels of $R$ (when $R>\lambda Y_{H}$ ) no project in $C$ can offer a sufficiently high return to attract capital and thus only the general technology 'demands' capital, up to the point where its return $x(\omega)=R$. At a lower level of $R$, equal to $\lambda Y_{H}$, projects in $C$ with $\bar{P}=\lambda Y_{H}$ can attract capital. The demand for capital is then the sum of the amount demanded by the general technology, $x^{-1}\left(\lambda Y_{H}\right)$, and the amount demanded by projects in $C$ with $\bar{P}=\lambda Y_{H}$. Notice that at $R=\lambda Y_{H}$ all firms in $C$ with $\bar{P}=\lambda Y_{H}$ benefit from raising capital. This explains the first flat portion of the demand curve, which is equal to the entire measure of continuing projects with $\bar{P}=\lambda Y_{H}, \int_{\left\{i \in C \mid \bar{P}^{i}=\lambda Y_{H}\right\}} d i$. At a lower level of $R$, equal to $\frac{\lambda}{2}\left(Y_{H}+Y_{M}\right)$, conglomerates of type $H M$ are able to raise two units of capital by pledging exactly $\frac{\lambda}{2}\left(Y_{H}+Y_{M}\right)$ for the second unit. The second flat portion of the curve is the measure of such conglomerates. At an even lower level of $R$ even projects of type $M$ can raise additional capital, which explains the remaining parts of the demand curve.

The vertical line is the total supply of capital. As we explain below supply is independent of the rate of return in our model.

Finally, the equilibrium return $R^{*}$ can be read on the vertical axis at the point where the demand for capital intersects the supply. In Panel $\mathrm{A}$, the equilibrium $R^{*}$ is bigger than the maximum amount that projects can pledge $\left(\lambda Y_{H}\right)$, and thus only the general technology receives capital. ${ }^{16}$ In panel $\mathrm{B}, R^{*}=\lambda Y_{H}$, and thus all projects in $C$ with $\bar{P}=\lambda Y_{H}$ can attract capital. However, given the amount of capital supplied there are not enough available funds for all of them. In this case, the

\footnotetext{
${ }^{15}$ Also, Figure 2 is constructed under the assumption that $x(0)>\lambda Y_{H}$, such that some capital must be invested in the general technology before it can flow to projects with $\bar{P}=\lambda Y_{H}$.

${ }^{16}$ Notice that in this case $r^{*}$, which is the probability that a project with $\bar{P}^{i}=R^{*}$ receives capital, can take any value in $[0,1]$ since there are no projects with $\bar{P}^{i}=R^{*}$. Thus, the equilibrium $r^{*}$ is not unique in this case.
} 
probability that such projects get capital $\left(r^{*}\right)$ is uniquely determined by Equation (5). Graphically, it is the ratio of the total amount of capital that is available to be allocated to high productivity projects in set $C$, which is equal to $K+\int_{\{i \in S\}} d i-x^{-1}\left(\lambda Y_{H}\right)$, to the total measure of such projects.

\subsection{Decision to demand, supply or opt out of the market}

In this section we analyze the participation decisions of firms, that is, the determination of sets $S$, $C$, and $O$. As we will show, this will allow us to characterize the demand and the supply of capital for any levels of conglomeration, $c$, and pledgeability, $\lambda$, and consequently the equilibrium capital allocation that is associated with each configuration of exogenous parameters.

Proposition 2 The participation decisions of firms are as follows

- Stand-alone firms of type $L$ and conglomerates of type LL supply all their capital to the market $(\operatorname{set} S)$.

- Conglomerates of types $L M$ and $L H$ do not participate in the external capital market and reallocate internally the capital in the $L$ project to their higher productivity project (set $O$ ).

- Stand-alone firms of types $H$ and $M$, and conglomerates of types $M M, M H$, and $H H$ seek finance in the external market for all their projects (set $C$ ).

The participation decisions of firms in proposition 2 follow from a restriction that the equilibrium return $R^{*}$ must obey in our model. Notice that because of market clearing, the equilibrium amount of capital allocated to the general technology $\left(\omega^{*}\right)$ must satisfy $0<\omega^{*} \leq 1+K$. From this it follows that $x(1+K) \leq R^{*}<x(0)$ and, by assumptions 1 and 2 :

$$
Y_{L} \equiv 0<R^{*}<Y_{M}<Y_{H}
$$

With this restriction, we can derive the sets $S, C$ and $O$. For stand-alone projects the participation decision is straightforward. Low productivity projects supply their capital to the market since they get $R^{*}$ in the market but get zero if they continue. Similarly, conglomerates of type $L L$ liquidate and supply their capital to the market. The projects of these firms constitute the set $S$.

The total supply of capital can now be computed as a function of $c$. There are $(1-c) p_{L}$ stand-alone firms with low productivity projects, each supplying one unit of capital, and $\frac{c}{2}\left(p_{L}\right)^{2}$ 
conglomerates of type $L L$, each supplying two units of capital. The supply of capital to the markets is then

$$
K+\int_{\{i \in S\}} d i=K+(1-c) p_{L}+c p_{L}^{2} .
$$

Equation (7) illustrates a key feature of the model: the higher is the degree of conglomeration, the lower is the supply of capital. The reason is that while a stand-alone firm with a project of type $L$ always supplies its capital to the market, conglomerates $M L$ and $H L$ always opt out of the market because they prefer internal reallocation. As the degree of conglomeration increases, the number of stand alone projects of productivity $L$ decreases and the number of conglomerates that opt out of the market increases.

Stand alone projects of productivities $M$ and $H$, and conglomerates of types $H H, M M$ and $M H$ generate more cash flow when they continue their projects (either $Y_{M}$ or $Y_{H}$ ) than when they supply their capital $\left(R^{*}\right)$. Moreover, stand-alone firms with projects $M$ and $H$ benefit from raising one unit of capital and conglomerates of type $H H, M M$ and $M H$ benefit from raising two units since they would only pay $R^{*}$ but can generate either $Y_{M}$ or $Y_{H}$. The projects of these firms constitute the set $C$.

We can also compute the precise measure of projects in $C$ with a particular $\bar{P}$, as a function of $c$ and $\lambda$. As an example, we compute the measure of projects with $\bar{P}=\lambda Y_{H}$. There are $(1-c) p_{H}$ stand-alone firms with a high productivity project, $\frac{c}{2} p_{H}^{2}$ conglomerates of type $H H$ each with two projects with $\bar{P}=\lambda Y_{H}$, and $c p_{H} p_{M}$ conglomerates of type $M H$ with one project with $\bar{P}=\lambda Y_{H} \cdot{ }^{17}$ Thus, there are $(1-c) p_{H}+c p_{H}^{2}+c p_{H} p_{M}$ projects in $C$ with $\bar{P}=\lambda Y_{H}$. Other measures can be computed similarly.

Finally, conglomerates of type $H L$ and $M L$ do not participate in the external capital market. They are (weakly) better off allocating capital internally than using the external capital market, because the best they can do in the market is to supply the unit of capital in their low productivity project and raise one unit for their higher productivity one. But they do not need the market to accomplish this transaction. Furthermore, if the probability of raising capital in the external market is less than one, they strictly prefer internal reallocation. The projects of these firms constitute the set $O$.

\footnotetext{
${ }^{17}$ Notice that for a conglomerate $G=\{j, k\}$ with $t(j)=t(k)=H$ we have $P^{j}=P^{k}=\lambda Y_{H}$, and for a conglomerate $G=\{j, k\}$ with $t(j)=M$ and $t(k)=H$, we have $P^{k}=\lambda Y_{H}$.
} 


\subsection{Conglomerates and the efficiency of capital allocation}

In the following proposition we state and prove the central result of the paper. We show that conglomeration can have a positive or a negative effect on the efficiency of capital allocation, depending on the range of the pledgeability parameter $\lambda$. In the proposition, the efficiency of capital allocation is measured as the "ex-ante" return on capital, calculated before the productivity of the projects that lie inside and outside conglomerates is known (see the appendix for the expression).

Proposition 3 There are functions $\widehat{\lambda}_{1}(c)<\widehat{\lambda}_{2}(c)$ such that:

a. For $\lambda<\widehat{\lambda}_{1}(c)$, the aggregate payoff is increasing in the degree of conglomeration,

b. For $\widehat{\lambda}_{1}(c)<\lambda<\widehat{\lambda}_{2}(c)$, the aggregate payoff is decreasing in the degree of conglomeration, and

c. For $\lambda>\widehat{\lambda}_{2}(c)$, the aggregate payoff is non-decreasing in the degree of conglomeration.

In order to understand the proposition, notice that the capital that conglomerates of type $M L$ and $H L$ reallocate internally goes from type $L$ to either type $M$, or type $H$ projects. If instead the projects of type $L$ were stand-alone firms, their capital would be supplied to the market. Whether conglomeration is good or bad for overall efficiency depends on what would have happened to the capital that these conglomerates reallocate internally, had it been supplied to the external market. If most or all of the released capital would have ended up in type $H$ projects, then conglomerates are bad for efficiency because part of the capital they reallocate internally goes to projects of type $M$. However, if little or none of the capital would have been reallocated to type $H$, the aggregate payoff increases with conglomeration.

For low levels of pledgeability $\left(\lambda<\widehat{\lambda}_{1}(c)\right)$ the external market does a poor job at allocating capital to type $H$ projects, and thus decreasing the number of conglomerates reduces the efficiency of capital allocation. This effect can be seen in Figure 3, Panel A, where the arrow shows the effect of a decrease in the level of conglomeration, corresponding to the hypothetical exercise of busting up conglomerates. A decrease in the degree of conglomeration increases the supply of capital to the market. However, as Panel A shows, all the newly released capital ends up in the general technology. Because the released capital was previously allocated internally by conglomerates to either their $M$ or $H$ projects, the decrease in conglomeration over this range reduces the allocative efficiency of the economy. 
For intermediate values of $\lambda, \widehat{\lambda}_{1}(c)<\lambda<\widehat{\lambda}_{2}(c)$, the market does a better job of allocating capital than in the previous case. In this range of $\lambda$ reducing the number of conglomerates is beneficial for the efficiency of capital allocation. This case is illustrated in Figure 3, Panel B. In this panel, both the initial and final levels of conglomeration are the same than in Panel A, however, the degree of pledgeability is higher. Because of this higher pledgeability, all the capital released to the market finds its way to high productivity projects. Thus, the decrease in conglomeration is beneficial since some of this newly released capital was previously allocated to mediocre projects by the $L M$ conglomerates.

Notice that the bias towards internal investment of these conglomerates is due to limited pledgeability. A conglomerate of type $L M$ does not supply capital to the market but rather allocates it internally (even when there is unsatisfied demand from projects of type $H$ ), since projects of type $H$ cannot offer a sufficiently high return. ${ }^{18}$ In this range, the maximum return a type $H$ project can offer is lower than the cash flows that a project of type $M$ generates (i.e., $\lambda Y_{H}<Y_{M}$ ) and thus it is privately optimal for the conglomerate to allocate internally whereas it is socially optimal to supply its capital to the market. ${ }^{19}$

Finally, for higher levels of pledgeability, increasing conglomeration is never detrimental to the aggregate payoff because all projects of type $H$ receive capital in the external capital market. As a result, transfers that take place inside the $L M$ conglomerates are no longer suboptimal since the best project in need of capital for the economy as a whole is now project $M$.

This proposition is the generalization of the result presented in the simple example of section 2. It shows that the simplifying assumptions that we made in that section are not necessary to

\footnotetext{
${ }^{18}$ One might wonder whether mergers between firms with $H$ projects and conglomerates of type $L M$ would not eliminate the inefficiency. The answer is that such mergers would be subject to the same imperfection that curb transactions in the external capital market (limited pledgeability). An acquisition at date $t_{1}$ of a type $H$ firm by a type $L M$ conglomerate, for example, basically consists of the type $H$ firm exchanging its future date $t_{2}$ cash flow for a current payment made by the conglomerate $L M$. The inefficiency would be completely eliminated only under the assumption that the conglomerate would be willing to pay the full $Y_{H}$ for the assets of firm $H$. This is unlikely to be the case if there is any specificity to the assets of $H$ that cannot be captured by the conglomerate, for example, if there is specific human capital invested in $H$. If the entrepreneur who runs firm $H$ is necessary to generate its full value, then it might be necessary to give him part of the rent generated by this firm ex-post (at date $t_{2}$ ), and thus the conglomerate $L M$ would not be willing to pay the full value of the firm ex-ante (at date $t_{1}$ ).

${ }^{19}$ We are assuming that firms cannot pledge cash flows of the first unit to raise the second unit of capital. However, this simplifying assumption is not necessary for the results. If the first unit was pledgeable all firms would have incentives to cross-pledge cash flows from the first unit in order to raise the second unit. This would complicate the analysis of the external market equilibrium because we would need to keep track of a larger number of potential values for $\bar{P}$. Nevertheless, there would still be a range for the pledgeability parameter in which conglomerates $M L$ would have a socially inefficient bias towards internal reallocation. The only difference is that because overall pledgeability is higher with this alternative assumption, both $\widehat{\lambda}_{1}(c)$ and $\widehat{\lambda}_{2}(c)$ would be lower.
} 
generate the equilibrium cost of internal capital markets. It also shows that a similar comparative statics exercise holds in the general model - the cost of conglomeration kicks in for intermediate pledgeability levels, for which the external capital market is most sensitive to the presence of conglomerates.

\section{The equilibrium level of conglomeration}

In the previous section we analyzed the effect of conglomeration on the efficiency of capital allocation, assuming that the level of conglomeration was exogenously given. In this section we analyze the equilibrium level of conglomeration. Proofs of the results discussed in this section are in the Appendix.

As we described above, at date $t_{0}$, entrepreneurs with projects can decide to form a two-project conglomerate or remain as stand-alone firms. We assume that there is a cost $d$ of conglomeration. This can be thought of as the organizational costs incurred by the conglomerate due to its higher complexity. In addition, $d$ can capture other benefits and costs of conglomeration. For example, Claessens, Djankov and Lang (2000) conclude from various case studies of business groups in East Asia that their "dominance lies in the privileges they solicit from the government." Countries where these privileges are high have a smaller $d$.

At date $t_{0}$, the equilibrium level of conglomeration must satisfy:

$$
U^{C}-2 U^{S A}=d
$$

where $U^{C}$ is the expected payoff of a two-project conglomerate and $U^{S A}$ is the expected payoff of a stand-alone project.

Figure 4, Panel A shows the same supply and demand schedule of Figure 2, for different levels of capital supply. In Figure 4, we write the total supply of capital as a function of the degree of conglomeration, $K+T(c)$, where by Equation $(7), T(c) \equiv(1-c) p_{L}+c p_{L}^{2}$. Figure 4, Panel B shows $U^{C}-2 U^{S A}$ as a function of the degree of conglomeration $c$. For each $c$ in Panel $\mathrm{B}$, there is a corresponding capital supply, $K+T(c)$, in Panel A. Notice that low levels of conglomeration are associated with a large supply of capital to the market ( $T$ decreases with $c$ ).

We explain the derivation of the curve $U^{C}-2 U^{S A}$ in Panel $\mathrm{B}$, starting at $c=\underline{c}$. When conglomeration is at this low starting level, the supply of capital is sufficiently large so that all good 
projects receive capital. This can be seen in Panel A where supply is $K+T(\underline{c})$. Starting from $c=\underline{c}$, an increase in conglomeration reduces the supply of funds and consequently raises the interest rate. This can be seen in Panel A as the supply of capital moves from $K+T(\underline{c})$ towards $K+T\left(c_{2}\right)$. Since a stand-alone firm supplies its capital to the external market more often than a conglomerate, it benefits from this increase more than a conglomerate does. This is shown in Panel B as a fall in $U^{C}-2 U^{S A}$ when conglomeration goes from $\underline{c}$ to $c_{2}$. For moderate levels of conglomeration (from $c_{2}$ to $c_{3}$ ), further increases in $c$ reduce supply so much that some good projects are unable to raise capital. This can be seen in Panel A by shifting the supply of capital from $K+T\left(c_{2}\right)$ to $K+T\left(c_{3}\right)$. Since stand-alone projects rely completely on the external market to raise capital whereas conglomerates rely only to some extent (they can use their internal capital markets) the payoff of a stand-alone firm falls relative to the payoff of a conglomerate. This is shown in Panel B as an increase in $U^{C}-2 U^{S A}$ when conglomeration goes from $c_{2}$ to $c_{3}$. Finally, for very high levels of conglomeration, no good project raises capital and any increase in conglomeration (contraction in supply) translates to an increase in the interest rate. This corresponds to cases in Panel A in which capital supply is below $K+T_{3}$. In this range stand-alone projects begin to benefit again from the increase in the interest rate, generating the reduction in $U^{C}-2 U^{S A}$ in Panel B for conglomeration levels above $c_{3}$.

As one can see from direct examination of Panel B, there are two equilibrium levels of conglomeration in this example, namely $\underline{c}$ and $\bar{c}$ with $\underline{c}<\bar{c} .{ }^{20}$ The intuition for the existence of multiple equilibria can be explained as follows. When $c$ is low, the supply of capital to the external market is large (because there are few conglomerates) and so all good projects in the economy (regardless of whether they are part of conglomerates) receive capital. In turn, because the market works well, it is beneficial for entrepreneurs to keep their projects as stand-alone firms rather than to conglomerate. Thus there is an equilibrium with low $c$. Alternatively, when $c$ is high, the supply of capital to the market is small (because there are so many conglomerates) and so no good project raises capital in the external capital market. In turn, because the external market works poorly, entrepreneurs choose to conglomerate. Thus, there is an equilibrium with high $c$.

We show in the Appendix that the existence of the multiple equilibria of the type explained in Figure 4 is a general feature of the model. More importantly, under certain conditions, we can show

\footnotetext{
${ }^{20}$ The third equilibrium (the middle one) is unstable and hence we do not discuss it further.
} 
that the low conglomeration equilibrium will be better from a social point of view. This result holds even when we do not count the cost of conglomeration $d$ in the aggregate payoff, and will only get stronger if we do. The fact that the low conglomeration equilibrium can be socially superior is not surprising given our previous findings that an exogenous increase in the degree of conglomeration can hurt the equilibrium allocation of capital. However, the results in this section contribute by showing that the main insight of the previous section remains even when we endogenize the degree of conglomeration in the economy. In the 'bad' equilibrium, there is too much conglomeration from a social point of view because even when capital is allocated efficiently inside the conglomerate the reallocation of capital across conglomerates is reduced.

Furthermore, the current results make it clear that the model might generate a mismatch between private and social incentives to conglomerate. Starting from the high conglomeration equilibrium, a bust up of conglomerates would improve the equilibrium capital allocation if conglomeration is socially inefficient. However, given that high conglomeration constitutes a stable equilibrium of the model, firms would not find it privately optimal to split up. This result suggests a potential role for policies that directly discourage the presence of conglomerates in developing economies.

\section{Empirical and policy implications}

In this section we discuss our theory's empirical and policy implications. We also discuss some anecdotal evidence that appears to be consistent with these implications.

Because our theory's main implications are based on the effects of conglomerates on the external market, a pre-condition for the model's mechanism to work is that the reduction in external market activity that the presence of conglomerates entails has to be a first order effect. Although there is no systematic study on this issue, the sheer size of business groups as a fraction of the economy in some countries suggests that this can be the case. Claessens, Fan, and Lang (2002) find that in 8 out of the 9 Asian countries they study, the top 15 family groups control more that $20 \%$ of the listed corporate assets. In a sample of 13 Western European countries, Faccio and Lang (2002) find that in 9 countries the top 15 family groups control more than $20 \%$ of the listed corporate assets. Given that business groups consist of such a large fraction of the capital market in some countries, it is highly plausible that their actions could have first-order effects on the behavior of the market 
as a whole.

Our theory makes the following empirical prediction about the relationship between conglomeration and the efficiency of capital allocation.

\section{The level of conglomeration in a country's corporate sector could be negatively related to the economy-wide efficiency of capital allocation, even if conglomerates' internal capital markets are privately efficient}

This result follows directly from proposition 3. Because of its negative effect on the ability of other firms to raise capital, conglomeration can decrease the efficiency of equilibrium capital allocation even when internal capital markets are efficient.

There are several important aspects related to implication 1 that need to be discussed. First, in order to test implication 1, one would need to measure the economy-wide efficiency of capital allocation. One possibility is suggested by Wurgler (2000), who uses the country-level elasticity of industry investment to industry value added to measure the efficiency of capital allocation. ${ }^{21}$ According to Wurgler, this elasticity provides a measure of whether capital is efficiently reallocated from declining industries towards growing ones. ${ }^{22}$ Second, one would need to build an "aggregate conglomeration" index for a large enough sample of countries. While we do not believe that such a measure is currently available for many countries, it can, in principle, be constructed. For example, for East Asia, Claessens, Djankov and Lang (2000) measure the fraction of firms that are affiliated with business groups. With a large enough sample of countries, future research could examine the empirical relationship between conglomeration and country-level measures of the efficiency of capital allocation such as Wurgler's.

A perhaps more fundamental concern is whether a negative relationship between conglomeration and the efficiency of capital allocation would allow us to clearly accept our theory against alternatives such as the possibility that conglomerates allocate capital inefficiently from a private standpoint (e.g., Scharfstein and Stein, 2000). If conglomerates do not allocate capital to their best available option, the efficiency of capital allocation should decrease with conglomeration indepen-

\footnotetext{
${ }^{21}$ Wurgler's main finding is that this elasticity is positively related to the level of financial development in crosscountry regressions.

${ }^{22}$ Almeida and Wolfenzon (2004) use Wurgler's measure to examine the relationship between an index of aggregate external finance dependence and the efficiency of capital allocation. They argue that Wurgler's within-year elasticity of investment to value-added is specially likely to capture the idea of capital reallocation.
} 
dently of whether our mechanism is in operation. Fortunately, one can use additional implications of the model in order to provide stronger evidence for it.

\section{The effect of conglomeration on allocative efficiency is non-monotonic in the} level of investor protection. In particular, the effect is more strongly negative for intermediate levels of investor protection

Result 2 also follows from proposition 3. This result is important because it provides for a way to differentiate our empirical implications from those of a model in which conglomerates allocate capital inefficiently. Existing models of inefficient investment in conglomerates, such as Scharfstein and Stein (2000) and Rajan, Servaes and Zingales (2000) do not make clear predictions regarding the relationship between the effect of conglomerates on efficiency and the level of investor protection. Other models have the implication that, as the financing-related benefits of conglomeration decrease, costs of conglomeration such as less effective monitoring (Stein, 1997), coordination costs (Fluck and Lynch, 1999), free cash-flow (Matsusaka and Nanda, 2002 and Inderst and Mueller, 2003) and incentive problems (Gautier and Heider, 2003) decrease the efficiency of conglomerates' investments. However, these papers generally imply a monotonic relationship between the underlying imperfection in capital allocation and the efficiency of conglomerates. ${ }^{23}$ Thus, we believe that the particular non-monotonicity that we identify is a novel implication of our model. ${ }^{24}$

An alternative way to test our model would be to examine the particular mechanism by which conglomerates adversely affect the efficiency of capital allocation.

\section{The level of conglomeration in a country's corporate sector should be positively} related to the financing constraints faced by independent firms, and thus negatively related to their growth

In our model, high-productivity independent firms are less likely to be able to raise capital in the external market if the degree of conglomeration is high. This is the main mechanism by which conglomerates adversely affect the equilibrium allocation of capital in the model, as explained in Section $4.4 .^{25}$

\footnotetext{
${ }^{23}$ The only exception seems to be Inderst and Mueller (2003). In their model, the (private) value of conglomeration is highest when the underlying imperfection is in an intermediate range. Notice this suggests the opposite of our implication that the social cost of conglomeration is highest for countries with moderate levels of investor protection.

${ }^{24}$ Notice, however, that a cross-sectional test of this non-monotonic relationship would require an even larger sample of countries than a test of implication 1 .

${ }^{25}$ In fact, the theory suggests that financing constraints could also be tightened for some types of conglomerates
} 
Because previous theory on internal capital markets generally ignores the effects that conglomeration might have on other firms in the economy, implication 3 is an additional implication that is particular to our model. It appears that such an implication would be testable, conditional on the construction of a conglomeration index for a large enough sample of countries (similarly to implications 1 and 2). The theory also suggests a way of sharpening a test of the mechanism by which conglomerates affect capital allocation.

4. The effect of conglomeration on the financing constraints faced by independent firms should be particularly strong for countries with intermediate levels of investor protection

The reasoning behind implication 4 is very similar to that behind implication 2 . If investor protection is very low, high productivity firms cannot raise capital irrespective of conglomeration, and if investor protection is very high all the inefficiencies disappear. Thus, the effect of conglomerates on other firms' financing constraints should be more pronounced for intermediate levels of investor protection. ${ }^{26}$

One general problem with any empirical test of implications 1 to 4 is that the level of conglomeration is (generally) endogenous to the level of investor protection and the efficiency of capital allocation in a country. While our theory also suggests that a model with endogenous conglomeration generates similar implications (section 5), for empirical purposes it might be desirable to isolate exogenous variations of conglomeration. As we discuss in section 4 , there is evidence that corporate grouping affiliation is affected to a large extent by history and political pressure. One might be able to use such sources of variation in order to identify experiments that facilitate testing and identification. ${ }^{27}$

Finally, our theory generates the following policy implication.

\section{Even if conglomerates have a negative effect on the efficiency of capital allocation,}

with high productivity projects. However, because conglomerates' internal capital markets relax their financing constraints, we believe it is cleaner to focus only on independent firms.

${ }^{26}$ The only difference between implications 2 and 4 is that conglomerates can never increase the probability with which independent firms raise capital. Thus the effect of conglomerates on other firms' financing constraints is (weakly) monotonic in the level of investor protection.

${ }^{27}$ One example, though in a different context, is Yafeh (1995), who uses the dissolution of the Japanese Zaibatsu following World War II as a large scale experiment to study the relationship between ownership structure and firm performance. 
individual conglomerates will have no private incentives to dismantle. Deconglomeration might require direct government intervention

Implication 5 is a direct consequence of the fact that the cost of conglomeration that we identify in our paper is an externality.

We end this section by discussing a recent example of the relation between conglomerates and the overall economy that appears to be consistent with our theory.

\section{The Case of South Korea}

The recent history of South Korea gives some anecdotal evidence for the predictions of our theory. Up until the 1990's, the Korean conglomerates, or chaebols, were credited with being one of the most important factors in Korea's rapid growth. This view appeared to change in the 1990's, as the chaebols began to be seen as an obstacle to growth. More importantly for our purposes, one of the reasons for this change in perception is that the chaebols are believed to inhibit the growth of small and medium sized firms, among other things, because most of the finance available was concentrated on the chaebols (see The Financial Times, April 23, 1998, "Small business living with the crumbs"). ${ }^{28}$ From the late 1990s, the Korean government has been exerting pressure on the chaebols to slim their empires. As a consequence, "with the chaebol no longer dominating access to South Korea's huge pool of savings, credit began to flow to small- and medium-sized firms" (The Economist, April 17, 2003, "Unfinished business").

The Korean example is broadly consistent with the picture painted by our model. First, when conglomeration was high, independent firms could not get capital. Second, despite this fact, the conglomerates did not voluntarily dismantle and thus government action was required. Third, after the conglomerates had started reforming, more financing was made available to independent firms. Finally, the fact that the role of the chaebols changed from being the driver of economic growth in the early stages of development to inhibiting development in its later stages could also be explained by our model because it predicts a positive effect of conglomeration for low level of institutional development and a negative effect at intermediate levels.

\footnotetext{
${ }^{28}$ Too much political power (as evidenced by a number of corruption scandals), almost total control of product markets and excessive debt levels are other reasons why the chaebols were believed to be hampering growth.
} 


\section{Conclusion}

We develop an equilibrium model to understand how the efficiency of capital allocation depends on the degree of conglomeration. We show that an increase in conglomeration can be detrimental to capital allocation even when conglomerates have efficient internal capital markets, because of the equilibrium effect of conglomerates on the efficiency of external capital markets. Our model is consistent with anecdotal evidence on the role of business groups in developing countries. In particular, the model gives a rationale for why the presence of business groups may inhibit the growth of new independent firms due to lack of finance. Our results also suggest that efficient internal capital markets is not a sufficient condition to advocate the presence of conglomerates in developing economies. Conglomeration may impose a negative externality to other firms by making it more difficult for good projects outside the conglomerate to raise funds. Finally, our model suggests that even when the economy as a whole benefits from having fewer funds allocated through internal capital markets, individual firms cannot be expected to bust up conglomerates on their own. Thus, there might be a role for policies that directly discourage the presence of conglomerates in developing economies.

One way to reinterpret our result is that, in an equilibrium framework, mitigating an agency cost for only a few firms is not necessarily beneficial for the overall economy. This insight could potentially be extended to the literature on financial intermediaries (e.g. Bencivenga and Smith, 1991; Boyd and Smith, 1992; King and Levine, 1993; Galetovic, 1996). This literature has argued that financial intermediaries perform several roles that aid the allocation of capital, such as discovering information about productivity, pooling funds and diversifying risks. In the context of our model, this reasoning suggests that financial intermediaries could increase pledgeability of cash flows in the economy. However, our results on conglomeration suggest that it is important that banks increase the aggregate pledgeability level (our parameter $\lambda$ ), as opposed to increasing pledgeability locally for a group of firms with more direct relationships with banks. If the latter occurs, banks might have similar effects to conglomerates: they might at the same time facilitate reallocation of capital across firms in their local relationships, and decrease the efficiency of overall reallocation because they compromise reallocation of capital across firms with different banking relationships. 


\section{References}

Almeida, H. and D. Wolfenzon, 2004, The effect of external finance on the equilibrium allocation of capital, forthcoming, Journal of Financial Economics.

Bencivenga, V. and B. Smith, 1991, Financial intermediation and endogenous growth, Review of Economic Studies 58, 195-209.

Bencivenga, V., Smith, B., Starr, R., 1995. Transaction costs, technological choice, and endogenous growth, Journal of Economic Theory 67, 153-77.

Boyd, J. and B. Smith, 1992, Intermediation and the equilibrium allocation of investment capital: implications for economic development, Journal of Monetary Economics 30, 409-432.

Castro, R., G. Clementi, and G. MacDonald, 2004, Investor protection, optimal incentives and economic growth, Quarterly Journal of Economics, forthcoming.

Claessens, S., J. Fan, and L. Lang, 2002, The cost of group affiliation: evidence from East Asia, working paper, University of Amsterdam.

Claessens, S., S. Djankov, and L. Lang, 2000, The separation of ownership and control in East Asian corporations, Journal of Financial Economics 58, 81-112.

Faccio, M. and L. Lang, 2002, The ultimate ownership of Western European corporations, Journal of Financial Economics 65, 365-395.

Fluck, Z., and A. Lynch, 1999, Why do firms merge and then divest? A theory of financial synergy, Journal of Business 72, 319-46.

Galetovic, A., 1996, Specialization, intermediation, and growth, Journal of Monetary Economics 38, 549-559.

Gertner, R., D. Scharfstein, and J. Stein, 1994, Internal versus external capital markets, Quarterly Journal of Economics 109, 1211-30.

Hart, O., and J. Moore, 1994, A theory of debt based on the inalienability of human capital, Quarterly Journal of Economics 109, 841-79

Gautier, A. and F. Heider, 2003, The benefits and costs of winner-picking: Redistribution versus incentives, working paper, New York University.

Holmstrom, B., and J. Tirole, 1997, Financial intermediation, loanable funds and the real sector, Quarterly Journal of Economics 112, 663-691.

Hoshi, T., and A. Kashyap, 2001, Corporate Financing and Governance in Japan, MIT Press, Cambridge, MA.

Hoshi, T., A. Kashyap, and D. Scharfstein, 1991, Corporate structure, liquidity and investment: Evidence from Japanese industrial groups, Quarterly Journal of Economics February, 33-60.

Inderst, R., and H. Mueller, 2003, Internal vs. external financing: An optimal contracting approach, Journal of Finance, forthcoming.

Khanna, T., and K. Palepu, 1997, Why focused strategies may be wrong for emerging countries, Harvard Business Review 75, 41-51. 
Khanna, T., and K. Palepu, 1999, The right way to restructure conglomerates in emerging markets, Harvard Business Review 77, 125-134.

Khanna, T., and Y. Yafeh, 2001, Business groups and risk sharing around the world, Harvard Business School Working Paper.

King , R., and R. Levine, 1993, Finance, entrepreneurship and growth, Journal of Monetary Economics 32, 513-542.

Lamont, O., 1997, "Cash Flow and Investment: Evidence from Internal Capital Markets," Journal of Finance 52, 83-110.

La Porta, R., F. Lopez-De-Silanes, and A. Shleifer, and R. Vishny, 1997, Legal determinants of external finance, Journal of Finance 52, 1131-1150.

La Porta, R., F. Lopez-De-Silanes, and A. Shleifer, and R. Vishny, 1998, Law and finance, Journal of Political Economy 106, 1113-1155.

Levine, R., 1991. Stock markets, growth and tax policy, Journal of Finance 46, 1445-65.

Maksimovic, V., and G. Phillips, 2001, The market for corporate assets: Who engages in mergers and asset sales and are there efficiency gains?, Journal of Finance 56, 2019-2065.

Maksimovic, V., and G. Phillips, 2002, Do conglomerate firms allocate resources inefficiently across industries?, Journal of Finance 57, 721-769.

Matsusaka, J., and V. Nanda, 2002, Internal capital markets and corporate refocusing, Journal of Financial Intermediation 11, 176-211.

Perotti, E. and S. Gelfer, 2001, Red barons or robber barons? Governance and investment in Russian financial-industrial groups, European Economic Review 45, 1601-1617.

Rajan, R., H. Servaes, and L. Zingales, 2000, The cost of diversity: The diversification discount and inefficient investment, Journal of Finance 55, 35-80.

Samphantharak, K., 2003, Internal capital markets in business groups, working paper, University of Chicago.

Scharfstein, D., and J. Stein, 2000, The dark side of internal capital markets: Divisional rentseeking and inefficient investment, Journal of Finance 55, 2537-64.

Shin, H., and R. Stulz, 1998, Are Internal Capital Markets Efficient?, Quarterly Journal of Economics 113, 531-52.

Shleifer, A., and D. Wolfenzon, 2002, Investor protection and equity markets, Journal of Financial Economics 66, 3-27.

Stein, J., 1997, Internal capital markets and the competition for corporate resources, Journal of Finance 52, 111-133.

Stein, J., 2003, Agency, information and corporate investment, in Constantinides, G., M. Harris and R. Stulz (eds.), Handbook of the Economics of Finance, Elsevier, North Holland.

Yafeh, Y., 1995, Corporate ownership, profitability and bank-firm ties: Evidence from the American occupation reforms in Japan, Journal of the Japanese and International Economies 9, 154-173, 
Wurgler, J., 2000, Financial markets and the allocation of capital, Journal of Financial Economics $58,187-214$. 


\section{Appendix}

Proof of Proposition 1

We divide the proof in several steps. First, given $\mathcal{E}$, sets $S, C$, and $O$, and any set of contracts offered by firms that have projects in $C$, we find the optimal allocation rule for investors. Next, given $\mathcal{E}$, and sets $S, C$, and $O$, we find the optimal contracts offered by firms. As promised in the text, in this part we also show that the optimal contracts $P^{j}$ and $P^{k}$ offered by a conglomerate $\{j, k\}$ are identical to what two stand-alone firms $\{j\}$ and $\{k\}$ would offer if the pledgeability constraint for these firms were $P^{s} \leq \bar{P}^{s} s=j, k$ with $\bar{P}^{s}$ defined as in the text. In the last step we impose market clearing to derive Equations (4) and (4).

Step 1 (allocation rule). We take as given $\mathcal{E}$, sets $S, C$, and $O$ and the set of contracts offered by firms seeking finance. Once the contracts are announced, investors allocate their capital. The following Lemma characterizes the contracts that are taken and the allocation of capital to the general technology.

Lemma 1 There is a threshold level, $R^{*}$, such that investors allocate $\omega^{*}=x^{-1}\left(R^{*}\right)$ to the general technology and

- take all contracts that offer strictly more than $R^{*}$ (i.e., if $P^{i}>R^{*}$, then $r^{i}=1$ ),

- do not take any contract that offers strictly less than $R^{*}$ (i.e., if $P^{i}<R^{*}$, then $r^{i}=0$ ), and

- take any fraction of the projects that offers exactly $R^{*}$.

Proof. With this allocation, all investment opportunities that do not receive capital yield a lower return than all investment opportunities that do receive capital. As a result, no investor can profitably switch his capital to an available investment opportunity. The precise level of $R^{*}$ is determined by a market clearing condition, as we show below.

As the Lemma above indicates, investor maximization behavior does not pin down the allocation rule to contracts offering exactly $R^{*}$. When there are more contracts offering weakly more than $R^{*}$ than there is capital available, not all contracts offering exactly $R^{*}$ receive capital. In this case, investors are indifferent as to the allocation rule to contracts offering exactly $R^{*}$. As we will see below, however, not all allocation rules to these contracts guarantee an equilibrium of the offering stage. We describe the equilibrium rule to contracts offering exactly $R^{*}$ in Lemma 2 .

Step 2 (optimal contracts). We still take $\mathcal{E}$, and the sets $S, C$, and $O$ as given, but now analyze the optimal contract offered by firms seeking finance. Conglomerates either supply both units of capital to the market, demand two units of capital, or opt out of the market completely. That is, there is no conglomerate that supplies one unit of capital to the market and demands one unit of capital. This is because such transaction is weakly dominated by internal reallocation. Therefore, we only analyze the optimal contracts offered by stand-alone firms that seek one unit of capital and conglomerates that seek two units.

Lemma 2 The allocation rule for projects offering an amount different than $R^{*}$ is in Lemma 1. The equilibrium allocation rule to projects offering exactly $R^{*}$ guarantees one unit of capital with certainty

- to contracts $P^{i}=R^{*}$ when offered by a stand alone firm $F=\{i\}$ with $\lambda Y_{t(i)}>R^{*}$,

- to contracts $P^{i}=R^{*}$ when offered by a conglomerate $G=\{i, j\}$ with $Y_{t(i)} \geq Y_{t(j)}$ and $Y_{t(i)}>R^{*}$, and

- to contracts $P^{i}=R^{*}$ when offered by a conglomerate $G=\{i, j\}$ with $Y_{t(i)}<Y_{t(j)}$ and $\lambda\left(Y_{t(j)}+Y_{t(k)}\right) / 2>R^{*}$,

and allocates capital with probability $r^{*}$ to all other contracts offering exactly $R^{*}$

The optimal contracts offered by firms seeking finance are as follows. A stand-alone firm $F=\{i\}$ announces $P^{i}=\begin{array}{cc}R^{*} & \text { if } \lambda Y_{t(i)} \geq R^{*} \\ 0 & \text { otherwise }\end{array}$. A conglomerate $G=\{i, j\}$ with $Y_{t(i)} \geq Y_{t(k)}$ announces $P^{i}=\begin{array}{cc}R^{*} & \text { if } \lambda Y_{t(i)} \geq R^{*} \\ 0 & \text { otherwise }\end{array}$ and $P^{k}=\begin{array}{cc}R^{*} & \text { if } \frac{\lambda}{2}\left(Y_{t(i)}+Y_{t(j)}\right) \geq R^{*} \\ 0 & \text { otherwise }\end{array}$.

Proof. According to Lemma 1, any allocation to projects offering exactly $R^{*}$ is consistent with investor maximization behavior. However, as we explain below, the particular rule in the Lemma 2 is the only one that guarantees the existence of optimal offers by projects.

We now show the optimality of the contracts offered by firms given the allocation rule by investors. By construction of the set $C$, projects in this set benefit by raising capital at $R^{*}$. Consider the stand alone firm $F=\{i\}$. When $\lambda Y_{t(i)}<R^{*}$, all feasible announcements by the firm must be strictly lower than $R^{*}$ and as a result the firm does not raise capital regardless of the proposed contract. Thus, it cannot profitably deviate from the equilibrium contract. 
When $\lambda Y_{t(i)}>R^{*}$, the optimal strategy calls for proposing $P^{i}=R^{*}$ and the allocation rule implies that the contracts is taken with probability 1 . The firm cannot deviate to a better contract. A higher announcement only increases the amount paid with no effect on the probability of receiving capital, and a lower announcement leads to no capital being allocated to the firm. When $\lambda Y_{t(i)}=R^{*}$, the equilibrium contract calls for $P^{i}=R^{*}$ and the allocation rule assigns capital to this firm with some probability $r^{*}$. Again, the firm cannot deviate from this strategy. It cannot announce a higher amount due to the pledgeability constraint, and it does not benefit by offering less because that would imply that the firm does not get capital at all..

Now, consider the conglomerate $G=\{i, j\}$ with $Y_{t(i)} \geq Y_{t(j)}$. By the pledgeability constraint in Equation (3) and the IC constraint $P^{i} \geq P^{j}$, it follows that

$$
P^{j} \leq \frac{\lambda}{2}\left(Y_{t(i)}+Y_{t(j)}\right)
$$

We consider all possible cases. 1) When $\lambda Y_{t(i)}<R^{*}$, it follows by Equation (2) that $P^{i}<R^{*}$ and, by the incentive compatibility constraint $P^{i} \geq P^{j}$, it must also be that $P^{j}<R^{*}$. Thus the conglomerate cannot raise capital with any feasible announcements. That is, it cannot do better than equilibrium strategy $P^{i}=P^{j}=0$. 2) When $\lambda Y_{t(i)}=R^{*}$ we consider two cases: a) $Y_{t(i)}>Y_{t(j)}$ and b) $Y_{t(i)}=Y_{t(j)}$. In case a), we have that $\frac{\lambda}{2}\left(Y_{t(i)}+Y_{t(j)}\right)<R^{*}$ so the equilibrium strategy calls for $P^{i}=R^{*}$ and $P^{j}=0$, and the conglomerate raises one unit of capital with probability $r^{*}$. In this case, Equation (9) becomes $P^{j}<R^{*}$ so the conglomerate cannot raise a second unit of capital with any feasible announcement. As a result, the conglomerate does not benefit from deviating from $P^{j}=0$. By the limited pledgeability constraint in Equation (2), the conglomerate cannot raise $P^{i}$. Also, reducing $P^{i}$ is not optimal since that leads to the conglomerate not raising any capital. In sum, the conglomerate cannot profitable deviate from $P^{i}=R^{*}$. In case b), we have that $\frac{\lambda}{2}\left(Y_{t(i)}+Y_{t(j)}\right)=R^{*}$ and so the optimal strategy calls for $P^{i}=P^{j}=R^{*}$ and each contract is taken with probability $r^{*}$. Increasing either $P^{i}$ or $P^{j}$ is precluded by limited liability constraints. Decreasing any of these announcements eliminates the possibility that that particular contract is taken. Thus, the conglomerate cannot profitably deviate from these announcements. 3) When $\lambda Y_{t(i)}>R^{*}>\frac{\lambda}{2}\left(Y_{t(i)}+Y_{t(j)}\right)$, the equilibrium strategy calls for $P^{i}=R^{*}$ and $P^{j}=0$ and the conglomerate raises one unit of capital with probability 1 . In this case, Equation (9) implies that $P^{j}<R^{*}$. That is, the conglomerate cannot raise a second unit with any feasible announcement and thus cannot profitably deviate from $P^{j}=0 . P^{i}=R^{*}$ is optimal because it allows the conglomerate to raise one unit with probability one with the minimum announcement possible. 4) When $\lambda Y_{t(i)}>R^{*}=\frac{\lambda}{2}\left(Y_{t(i)}+Y_{t(j)}\right)$, the equilibrium strategy is $P^{i}=P^{j}=R^{*}$. Contract $P^{i}$ is taken with probability 1 and contract $P^{j}$ is taken with probability $r^{*}$. Decreasing any of these two offers would lead to that particular contract not being taken. Also, the conglomerate cannot raise any of the offers because the pledgeability constraint in Equation (3) binds for these values. 5) Finally, $\frac{\lambda}{2}\left(Y_{t(i)}+Y_{t(j)}\right)>R^{*}$ the equilibrium strategy calls for $P^{i}=P^{j}=R^{*}$ and the equilibrium allocation is such that the conglomerate receives two units of capital for sure. Clearly, there is no profitable deviation because the conglomerate is getting each unit of capital with the minimum announcement possible.

Finally, note that, with the definition of $\bar{P}$ in the text, the contract offered to raise capital for any project $i$ in the economy, can be written as $P^{i}=\begin{array}{rr}R^{*} & \text { if } \bar{P}^{i} \geq R^{*} \\ 0 & \text { otherwise }\end{array}$ regardless of whether the project is in a stand-alone firm or in a conglomerate. Also, the probability of a project $i$ receiving capital when $P^{i}=R^{*}$ is 1 if $\bar{P}^{i}>R^{*}$ and $r$ if $\bar{P}^{i}=R^{*}$ regardless of whether the project is in a stand-alone or in a conglomerate. For this reason, once we incorporate the information about the type of firm project $i$ belongs to in the definition of $\bar{P}^{i}$, we can treat project $i$ as a stand-alone firm.

The allocation rule in Lemma 2 is the only one that guarantees the existence of an optimal strategy for projects. The key feature of the allocation rule is that it allocates capital for sure to projects that can potentially offer more. If the allocation rule does not guarantee a unit of capital with certainty to those firms that can potentially offer more, then these firms could offer $R^{*}+\varepsilon$ and get capital with probability 1 (by Lemma 1). But, in this case, an equilibrium would not exist because $\varepsilon$ can always be made smaller. Thus, the allocation rule above is the only one for which an equilibrium always exist.

Step 3 (Market clearing). Combining the optimal announcement for each project $i \in C$ in Lemma 2 with the equilibrium allocation rule, we get that a project $i \in C$ receives capital with certainty if $\bar{P}^{i}>R^{*}$, receives capital with probability $r^{*}$ if $\bar{P}^{i}=R^{*}$, and does not receive capital if $\bar{P}^{i}<R^{*}$. The market clearing condition is then:

$$
x^{-1}\left(R^{*}\right)+\int_{\left\{i \in C \mid \bar{P}^{i}>R^{*}\right\}} d i+\int_{\left\{i \in C \mid \bar{P}^{i}=R^{*}\right\}} r^{*} d i=K+\int_{\{i \in S\}} d i .
$$

Because $r^{*}$ must be between zero and one, the value of $R^{*}$ satisfies

$$
x^{-1}\left(R^{*}\right)+\int_{\left\{i \in C \mid \bar{P}^{i}>R^{*}\right\}} d i \leq K+\int_{\{i \in S\}} d i \leq x^{-1}\left(R^{*}\right)+\int_{\left\{i \in C \mid \bar{P}^{i} \geq R^{*}\right\}} d i .
$$




\section{Proof of Proposition 2}

In the text.

Proof of Proposition 3

We start by determining the probabilities that projects in $C$ receive capital as a function of $c$ and $\lambda$. This is a simple application of Propositions 1 and 2. From Proposition 2, set $C$ is formed by projects that belong to stand-alone firms $M$ and $H$, and by projects that belong to type $M H$ conglomerates. Note that there are only three possible values of $\bar{P}$ for projects in this set: $\lambda Y_{H}$ (for projects that belong to the $H$ stand-alone firms and for the type $H$ project that belong to the $M H$ conglomerate ), $\lambda \frac{\left(Y_{H}+Y_{M}\right)}{2}$ (for the $M$ projects that belong to the $M H$ conglomerate), and $\lambda Y_{M}$ (for projects that belong to the $M$ stand-alone firms). We denote these values as $\bar{P}_{H}, \bar{P}_{H M}$, and $\bar{P}_{M}$. We also let $r_{H}, r_{H M}$, and $r_{M}$ be the probability that projects with $\bar{P}$ equal $\bar{P}_{H}, \bar{P}_{H M}$, and $\bar{P}_{M}$, respectively, receive capital in the external market. We let $T$ be the amount of liquidation, i.e., $T \equiv(1-c) p_{L}+c p_{L}^{2}$. We also let $Y_{H M} \equiv\left(Y_{H}+Y_{M}\right) / 2$

We explain the derivation of $r_{H}$, the probability that projects with $\bar{P}=\bar{P}_{H}$ receive capital. As explained in the text there are $(1-c) p_{H}+c p_{H}^{2}+c p_{H} p_{M}$ projects in $C$ with $\bar{P}=\lambda Y_{H}$. This measure can be written more succinctly as $p_{H}-c p_{L} p_{H}$. For a given level of conglomeration $c$, we can write $r_{H}$ as:

$$
r_{H}=\left\{\begin{array}{cl}
0 & \text { if } \lambda Y_{H}<x(K+T) \\
\frac{K+T-x^{-1}\left(\lambda Y_{H}\right)}{p_{H}-c p_{L} p_{H}} & \text { if } x(K+T) \leq \lambda Y_{H}<x\left(K+T-p_{H}+c p_{L} p_{H}\right) \\
1 & \text { if } \lambda Y_{H} \geq x\left(K+T-p_{H}+c p_{L} p_{H}\right)
\end{array}\right.
$$

The probability that projects with $\bar{P}=\lambda Y_{H}$ get capital depends on whether the required return on capital (the return of the general technology) is higher or lower than $\lambda Y_{H}$. If $\lambda Y_{H}<x(K+T)$, then these projects cannot get capital because even when the entire capital supply is invested in the general technology the required return on capital is too high. If $\lambda Y_{H} \geq x(K+T)$, then projects can get some capital. However, if $\lambda Y_{H}<x\left(K+T-p_{H}+c p_{L} p_{H}\right)$ then if all of the projects get capital the return on capital becomes lower than their pledgeable income. In this case projects with $\bar{P}=\lambda Y_{H}$ are rationed, and the return on capital is such that $x\left(\omega^{*}\right)=\lambda Y_{H}$, or $\omega^{*}=x^{-1}\left(\lambda Y_{H}\right)$. An amount of capital equal to $x^{-1}\left(\lambda Y_{H}\right)$ is invested in the general technology, and thus the probability that a project gets capital is equal to $\frac{K+T-x^{-1}\left(\lambda Y_{H}\right)}{p_{H}-c p_{L} p_{H}}$. Finally, if $\lambda Y_{H} \geq x\left(K+T-p_{H}+c p_{L} p_{H}\right)$ then all projects can get capital, and $r_{H}=1$.

Exactly analogous reasoning leads to the following equations for $r_{H M}$ and $r_{M}$ :

$$
\begin{aligned}
& r_{H M}=\left\{\begin{array}{cc}
0 & \text { if } \lambda Y_{H M}<x\left(K+T-p_{H}+c p_{L} p_{H}\right) \\
\frac{K+T-p_{H}+c p_{L} p_{H}-x^{-1}\left(\lambda Y_{H M}\right)}{c p_{H} p_{M}} & \text { if } x\left(K+T-p_{H}+c p_{L} p_{H}\right) \leq \lambda Y_{H M}< \\
1 & <x\left(K+T-p_{H}+c p_{L} p_{H}-c p_{M} p_{H}\right)
\end{array}\right. \\
& r_{M}=\left\{\begin{array}{cc}
\text { if } \lambda Y_{H M} \geq x\left(K+T-p_{H}+c p_{L} p_{H}-c p_{M} p_{H}\right) \\
0 & \text { if } \lambda Y_{M}<x\left(K+T-p_{H}+c p_{L} p_{H}-c p_{M} p_{H}\right) \\
\frac{K+T--p_{H}+c p_{L} p_{H}-c p_{H} p_{M}-x^{-1}\left(\lambda Y_{M}\right)}{(1-c) p_{M}+c p_{M}^{2}} & \text { if } x\left(K+T-p_{H}+c p_{L} p_{H}-c p_{M} p_{H}\right) \leq \lambda Y_{M}< \\
1 & <x\left(K+T-p_{H}+c p_{L} p_{H}-c p_{M} p_{H}-(1-c) p_{M}-c p_{M}^{2}\right)
\end{array}\right. \\
& \begin{array}{cc}
\text { if } \lambda Y_{M} \geq x\left(K+T-p_{H}+c p_{L} p_{H}-c p_{M} p_{H}-(1-c) p_{M}-c p_{M}^{2}\right) \\
1
\end{array}
\end{aligned}
$$

The definition of $r_{H}, r_{H M}$ and $r_{M}$ motivate the definition of the following functions of $\lambda: \widetilde{\lambda}_{1}=x(K+T) / Y_{H}$, $\widetilde{\lambda}_{2}=x\left(K+T-p_{H}+c p_{L} p_{H}\right) / Y_{H}, \widetilde{\lambda}_{3}=x\left(K+T-p_{H}+c p_{L} p_{H}\right) / Y_{H M}, \widetilde{\lambda}_{4}=x\left(K+T-p_{H}+c p_{L} p_{H}-c p_{M} p_{H}\right) / Y_{H M}$, $\widetilde{\lambda}_{5}=x\left(K+T-p_{H}+c p_{L} p_{H}-c p_{M} p_{H}\right) / Y_{M}$ and $\widetilde{\lambda}_{6}=x\left(K+T-p_{H}+c p_{L} p_{H}-c p_{M} p_{H}-(1-c) p_{M}-c p_{M}^{2}\right) / Y_{M}$. For any $c$, the value of these functions satisfy $\widetilde{\lambda}_{1}<\widetilde{\lambda}_{2}<\cdots<\widetilde{\lambda}_{6}$.

To lighten notation we let $r_{t}^{\prime} \equiv \frac{\partial r_{t}}{\partial c}$ for $t=H, H M$, and $M$ and $f(\omega)=\omega x(\omega)$. The aggregate payoff function is given by:

$$
\begin{array}{cc}
\Pi= & f(\omega)+(1-c)\left[p_{H}\left(Y_{H}+r_{H} Y_{H}\right)+p_{M}\left(Y_{M}+r_{M} Y_{M}\right)\right]+ \\
\frac{c}{2} & p_{H}^{2}(2)\left(Y_{H}+r_{H} Y_{H}\right)+p_{M}^{2}(2)\left(Y_{M}+r_{M} Y_{M}\right)+2 p_{H} p_{M}\left(2 Y_{H}+r_{H} Y_{M}+r_{H} Y_{M}\right) \\
& +2 p_{H} p_{L}\left(2 Y_{H}\right)+2 p_{M} p_{L}\left(2 Y_{M}\right)
\end{array}
$$

where $\omega=K+(1-c) p_{L}+c p_{L}^{2}-r_{H}\left(p_{H}-c p_{L} p_{H}\right)-r_{H M}\left(c p_{H} p_{M}\right)-r_{M}\left((1-c) p_{M}+c p_{M}^{2}\right)$. We analyze $\frac{d \Pi}{d c}$ in all the regions defined by $\widetilde{\lambda}_{k} k=1,2 \ldots 6$. We denote by $\frac{\partial \Pi}{\partial c}$ the derivative of $\Pi$ wrt $c$ assuming that $r_{H}, r_{H M}$ and $r_{M}$ are constants:

$$
\begin{aligned}
\frac{\partial \Pi}{\partial c} & =p_{L} p_{H}\left(1-r_{H}\right)\left(Y_{H}-f^{\prime}(\omega)\right)+p_{H} p_{M}\left(1-r_{H}\right)\left(Y_{H}-Y_{M}\right)+ \\
& +p_{M}\left(1-p_{M}\right)\left(1-r_{M}\right)\left(Y_{M}-f^{\prime}(\omega)\right)+p_{H} p_{M}\left(r_{H M}-1\right)\left(Y_{M}-f^{\prime}(\omega)\right)
\end{aligned}
$$

For $\lambda<\widetilde{\lambda}_{1}, r_{H}=r_{H M}=r_{M}=0$ and since $r_{H}^{\prime}=r_{H M}^{\prime}=r_{M}^{\prime}=0$ we can use equation 11 to obtain $\frac{d \Pi}{d c}=\frac{\partial \Pi}{\partial c}=$ $p_{L} p_{H}\left(Y_{H}-f^{\prime}(\omega)\right)+p_{H} p_{M}\left(Y_{H}-Y_{M}\right)+p_{M} p_{L}\left(Y_{M}-f^{\prime}(\omega)\right)>0$ since $f^{\prime}(\omega)=x(\omega)+\omega x^{\prime}(\omega) \leq x(\omega)<Y_{M}<Y_{H}$. 
For $\widetilde{\lambda}_{1}<\lambda<\widetilde{\lambda}_{2}, r_{H} \in(0,1), r_{H M}=0$ and $r_{M}=0$ also $r_{H}^{\prime} \neq 0$ and $r_{H M}^{\prime}=r_{M}^{\prime}=0$. Also in this region, simple algebra leads to $\frac{\partial \omega}{\partial c}=0$. Thus, $\frac{d \Pi}{d c}=p_{L} p_{H}\left(1-r_{H}\right) Y_{H}+p_{H} p_{M}\left(1-r_{H}\right)\left(Y_{H}-Y_{M}\right)+p_{M} p_{L} Y_{M}+r_{H}^{\prime}\left[(1-c) p_{H} Y_{H}+c p_{H}^{2} Y_{H}+\right.$ $\left.c p_{H} p_{M} Y_{M}\right]$ and $r_{H}^{\prime}=\frac{-p_{L}+p_{L}^{2}+r_{H} p_{H} p_{L}}{p_{H}-c p_{L} p_{H}}$. In the limit as $\lambda \rightarrow \widetilde{\lambda}_{2}, r_{H} \rightarrow 1$ and $\frac{d \Pi}{d c}=p_{M} p_{L} Y_{M}-p_{M} p_{L}\left[\gamma Y_{H}+(1-\gamma) Y_{M}\right]<$ 0 where $\gamma=\left(1-c+c p_{H}\right) /\left(1-c p_{L}\right)$. Also $\frac{\partial}{\partial \lambda} \frac{d \Pi}{d c}=\frac{\partial}{\partial r_{H}} \frac{d \Pi}{d c} \frac{\partial r_{H}}{\partial \lambda}$. Since $x()$ is a decreasing function $\frac{\partial r_{H}}{\partial \lambda}$ is increasing. And since $\frac{\partial}{\partial r_{H}} \frac{d \Pi}{d c}=-p_{H} p_{L} Y_{H}-p_{H} p_{M}\left(Y_{H}-Y_{M}\right)+p_{H} p_{L}\left[\gamma Y_{H}+(1-\gamma) Y_{M}\right]<0$ then $\frac{\partial}{\partial \lambda} \quad \frac{d \Pi}{d c}<0$.

If $\frac{d \Pi}{d c} \tilde{\lambda}_{1} \leq 0$ then we define $\widehat{\lambda}_{1}=\widetilde{\lambda}_{1}$. If $\frac{d \Pi}{d c} \tilde{\lambda}_{1}>0$ then since $\frac{\partial}{\partial \lambda} \frac{d \Pi}{d c}<0$ and $\frac{d \Pi}{d c} \tilde{\lambda}_{2}<0$, there is a $\lambda^{*} \in\left(\widetilde{\lambda}_{1}, \widetilde{\lambda}_{2}\right)$ such that $\left.\frac{d \Pi}{d c}\right|_{\lambda^{*}}=0$. In this case we define $\widehat{\lambda}_{1}=\lambda^{*}$. We also define $\widehat{\lambda}_{2}=\widetilde{\lambda}_{2}$. So far we have shown that to the left of $\widehat{\lambda}_{1}, \frac{d \Pi}{d c}$ is positive, and from $\widehat{\lambda}_{1}$ to $\widehat{\lambda}_{2}, \frac{d \Pi}{d c}$ is negative. Left to prove is that to the right of $\widehat{\lambda}_{2}$, $\frac{d \Pi}{d c}$ is non-negative.

For $\widetilde{\lambda}_{2}<\lambda<\widetilde{\lambda}_{3}, r_{H}=1, r_{H M}=r_{M}=0$ and $r_{H}^{\prime}=r_{H M}^{\prime}=r_{M}^{\prime}=0$. Using equation $11, \frac{d \Pi}{d c}=\frac{\partial \Pi}{\partial c}=$ $p_{M} p_{L}\left(Y_{M}-f^{\prime}(\omega)\right)>0$.

For $\widetilde{\lambda}_{3}<\lambda<\widetilde{\lambda}_{4}, r_{H}=1, r_{H M} \in(0,1), r_{M}=0$ and $r_{H M}^{\prime} \neq 0$ and $r_{H}^{\prime}=r_{M}^{\prime}=0$. Also in this region, simple algebra leads to $\frac{\partial \omega}{\partial c}=0$. Thus, $\frac{d \Pi}{d c}=p_{M} p_{L} Y_{M}+p_{H} p_{M} r_{H M} Y_{M}+c p_{H} p_{M} r_{H M}^{\prime} Y_{M}$ and $r_{H M}^{\prime}=\frac{-p_{L}+p_{L}^{2}-+p_{H} p_{L}+r_{H M} p_{H} p_{M}}{c p_{H} p_{M}}$. Substituting the value of $r_{H M}^{\prime}$ and simplifying leads to $\frac{d \Pi}{d c}=0$.

For $\tilde{\lambda}_{4}<\lambda<\widetilde{\lambda}_{5}, r_{H}=1, r_{H M}=1, r_{M}=0$ and $r_{H}^{\prime}=r_{H M}^{\prime}=r_{M}^{\prime}=0$. Using equation $11, \frac{d \Pi}{d c}=\frac{\partial \Pi}{\partial c}=$ $p_{M}\left(1-p_{M}\right)\left(Y_{M}-\tilde{\sim}^{\prime}(\omega)\right)>0$

For $\tilde{\lambda}_{5}<\lambda<\widetilde{\lambda}_{6}, r_{H}=1, r_{H M}=1, r_{M} \in(0,1)$ and $r_{M}^{\prime} \neq 0$ and $r_{H M}^{\prime}=r_{M}^{\prime}=0$. Also in this region, simple algebra leads to $\frac{\partial \omega}{\partial c}=0$. $\frac{d \Pi}{d c}=p_{M} p_{L} Y_{M}+p_{H} p_{M} Y_{M}-p_{M} r_{M} Y_{M}+p_{M}^{2} r_{M} Y_{M}+r_{M}^{\prime}\left((1-c) p_{M} Y_{M}+c p_{M}^{2} Y_{M}\right)$ and $r_{M}^{\prime}=\frac{-p_{L}+p_{L}^{2}+p_{L} p_{H}-p_{H} p_{M}-r_{M}\left(-p_{M}+p_{M}^{2}\right)}{(1-c) p_{M}+c p_{M}^{2}}$. Substituting the value of $r_{M}^{\prime}$ and simplifying leads to $\frac{d \Pi}{d c}=0$.

Finally, for $\lambda>\widetilde{\lambda}_{6}, r_{H}=1, r_{H M}=1, r_{M}=1$ and $r_{H}^{\prime}=r_{H M}^{\prime}=r_{M}^{\prime}=0$. Using equation $11, \frac{d \Pi}{d c}=\frac{\partial \Pi}{\partial c}=0$.

Thus, to the right of $\widehat{\lambda}_{2}, \frac{d \Pi}{d c}$ is non-negative.

Proof of results of section 5

We modify the model so that firms choose whether to conglomerate at date $t_{0}$. If two firms choose to conglomerate they pay a cost $d$. This cost can be thought of as organizational costs that the conglomerate incurs due to its higher complexity.

Let $U^{S A}$ be the expected payoff of a stand-alone project and $U^{C}$ be the expected payoff of a conglomerate (excluding the cost $d$ ). Then

$$
\begin{aligned}
U^{S A} & =p_{H}\left(Y_{H}+r_{H}\left(Y_{H}-R\right)\right)+p_{M}\left(Y_{M}+r_{M}\left(Y_{M}-R\right)\right)+p_{L} R \\
U^{C} & =p_{H}^{2}\left(2 Y_{H}+2 r_{H}\left(Y_{H}-R\right)\right)+p_{M}^{2}\left(2 Y_{M}+2 r_{M}\left(Y_{M}-R\right)\right)+2 p_{H} p_{M}\left(2 Y_{H}+r_{H}\left(Y_{M}-R\right)+r_{H}\left(Y_{M}-R\right)\right) \\
& +2 p_{H} p_{L}\left(2 Y_{H}\right)+2 p_{M} p_{L}\left(2 Y_{M}\right)
\end{aligned}
$$

\section{Characterizing the equilibrium level of conglomeration}

To concentrate on the most interesting region of the parameter space, we assume that

\section{Assumption 3}

$$
\begin{aligned}
& \text { a. } x\left(K+p_{L}^{2}\right)>\lambda Y_{H} \\
& \text { b. } x\left(K+p_{L}-p_{H}\right)<\lambda Y_{H M}
\end{aligned}
$$

Figure 3, panel A shows the reallocation market for different levels of conglomeration. In this figure $K+T_{3} \equiv$ $x^{-1}\left(\lambda Y_{H}\right)$ and $K+T_{2} \equiv x^{-1}\left(\lambda Y_{H}\right)+p_{H}-c p_{L} p_{H}$, and $K+T_{3} \equiv x^{-1}\left(\lambda Y_{H M}\right)+p_{H}-c p_{L} p_{H}$. Figure 3, panel B shows $U^{C}-2 U^{S A}$ as a function of $c$. In this figure, $c_{1}=\frac{K+p_{L}-x^{-1}\left(\lambda Y_{H M}\right)-p_{H}}{p_{L}-p_{L}^{2}-p_{L} p_{H}}, c_{2}=\frac{K+p_{L}-x^{-1}\left(\lambda Y_{H}\right)-p_{H}}{p_{L}-p_{L}^{2}-p_{L} p_{H}}$, and $c_{3}=\frac{K+p_{L}-x^{-1}\left(\lambda Y_{H}\right)}{p_{L}-p_{L}^{2}}$. (Assumption 3 (a) guarantees that $c_{3}<1$ and assumption $3(\mathrm{~b})$ guarantees that $\left.c_{1}>0\right)$. These values are chosen so that when $c \in\left(c_{1}, c_{2}\right]$ then the supply of capital $K+T \in\left[K+T_{2}, K+T_{1}\right)$, when $c \in\left(c_{2}, c_{3}\right]$ then $K+T \in\left[K+T_{3}, K+T_{2}\right)$, and when $c \in\left(c_{3}, 1\right]$ then $K+T<K+T_{3}$. To compute $U^{C}-2 U^{S A}$, we need the date $t_{1}$ equilibrium allocation $\left(r_{H}, r_{H M}\right.$, and $\left.r_{M}\right)$ and return $R$. We get these values from figure 2, panel A. For example, in the region where $K+T \in\left[K+T_{2}, K+T_{1}\right), r_{H}=1$ and $r_{H M}=r_{M}=0$ and $R$ is calculated where demand intersects supply. In the region where $K+T \in\left[K+T_{3}, K+T_{2}\right), r_{H} \in(0,1], r_{H}=r_{M}=0$ and $R=\lambda Y_{H}$. Finally, in the region where $K+T>K+T_{3}, r_{H}=r_{H M}=r_{M}=0$ and $R$ is again calculated where demand intersects supply. Next we take the date $t_{1}$ equilibrium values and plug them in $U^{S A}-2 U^{C}$. 
In Figure 3, panel B, the level of $d$ satisfies

$$
\begin{aligned}
& d \in\left[\max \left\{2 p_{H} p_{L}\left(Y_{H}-x\left(K+p_{L}^{2}\right)\right)+2 p_{M} p_{L}\left(Y_{M}-x\left(K+p_{L}^{2}\right)\right)+2 p_{H} p_{M}\left(Y_{H}-Y_{M}\right), 2 p_{M} p_{L}\left(Y_{M}-\lambda Y_{H}\right)\right\},\right. \\
& \min \left\{2 p_{H} p_{L}\left(Y_{H}-\lambda Y_{H}\right)+2 p_{M} p_{L}\left(Y_{M}-\lambda Y_{H}\right)+2 p_{H} p_{M}\left(Y_{H}-Y_{M}\right), 2 p_{M} p_{L}\left(Y_{M}-\lambda Y_{H}\right)\right] .
\end{aligned}
$$

In this case there are two equilibria, the high conglomeration equilibrium at $\bar{c}$ and the low conglomeration equilibrium at $\underline{c}$ (the equilibrium level of $c$ between other $\underline{c}$ and $\bar{c}$ is not stable so we do not consider it in the discussion). As can be seen from figure 3, panel A, in the high conglomeration equilibrium there is little supply of funds to the market and as a result the reallocation market works poorly (no reallocation to good projects). As a result it does not pay to be a stand alone. In the low conglomeration equilibrium, the supply of funds is larger and as a result the external market works better. Since good projects do get capital in equilibrium, it pays to be a stand-alone project.

\section{Welfare comparison between the two equilibria}

For a sufficiently steep $x($.$) function, the equilibrium with low conglomeration is better from society's point of$ view. In this proof, we also assume that $d$ satisfies the condition in equation 12 .

First we define what we mean by a 'steeper' $x($.$) function. We start with any x($.$) function that leads to two$ equilibrium levels of conglomeration $\underline{c}$ and $\bar{c}$ with respective date $t_{1}$ equilibrium return $\underline{R}$ and $\bar{R}$. We also define $\bar{\omega}$ as the amount of capital going to the general technology in the high conglomeration equilibrium. We consider a family of $x($.$) functions that pass through the high conglomeration equilibrium, that is all x($.$) function in this family satisfy$ $x(\bar{\omega})=\bar{R}$. For each $x($.$) we define \Delta \omega$ as $x(\bar{\omega}+\Delta \omega)=\underline{R}$. That is, $\Delta \omega$ is the additional amount of capital that has to be invested in the general technology to drive the return down from $\bar{R}$ to $\underline{R}$. Intuitively, the smaller the $\Delta \omega$, the 'steeper' the $x($.$) function.$

We show that there is a level $\widehat{\Delta \omega}$ such that for all $x($.$) functions in the family defined above with \Delta \omega<\widehat{\Delta \omega}$, the low conglomeration equilibrium is the better one.

First, notice that for a given set of parameters $\left\{Y_{H}, Y_{M}, p_{H}, p_{L} \cdot p_{M}, d\right\}$ the equilibrium returns $\bar{R}$ to $\underline{R}$ satisfy:

$$
\begin{aligned}
& 2 p_{M} p_{L}\left(Y_{M}-\underline{R}\right)=d \\
& 2 p_{H} p_{L} Y_{H}-2 p_{M} p_{L} Y_{M}-\bar{R}\left(2 p_{H} p_{L}+2 p_{M} p_{L}\right)+2 p_{H} p_{M}\left(Y_{H}-Y_{M}\right)=d
\end{aligned}
$$

These expressions are the expansion of $U^{S A}-2 U^{C}$ at the low and high conglomeration equilibria. From the expressions, it is clear that the return in the date $t_{1}$ reallocation market is not affected by the $x($.$) function . However,$ the level of $c$ at the low conglomeration equilibrium will be not be the same as different amounts of capital need to be released to the external market to achieve a return of $\underline{R}$. In other words, for the family of $x($.$) functions we consider,$ there are two equilibria: $(\bar{c}, \bar{R})$, and $(\underline{c}(\Delta \omega), \underline{R})$. The only unknown is $\underline{c}(\Delta \omega)$.

To solve for $\underline{c}(\Delta \omega)$, we use the market clearing conditions at the two equilibria:

$$
\begin{aligned}
& K+(1-\bar{c}) p_{L}+\bar{c} p_{L}^{2}=\bar{\omega} \\
& K+(1-\underline{c}) p_{L}+\underline{c} p_{L}^{2}=\bar{\omega}+\Delta \omega+p_{H}-\underline{c} p_{L} p_{H}
\end{aligned}
$$

These expressions follow from the fact that at the high conglomeration equilibrium $r_{H}=r_{H M}=r_{M}=0$ and at the low conglomeration equilibrium $r_{H}=1$ and $r_{H M}=r_{M}=0$. Letting $\underline{c}=\bar{c}-\Delta c$, subtracting one equation from the other, and simplifying leads to:

$$
\Delta c=\frac{p_{H}-\bar{c} p_{L} p_{H}+\Delta \omega}{p_{L} p_{M}}
$$

We use equation 10 to compute $\Pi(\underline{c})-\Pi(\bar{c})$. We do not consider the cost $d$ of conglomeration in the aggregate payoff. Including this cost only helps our result since the number of conglomerates is smaller and consequently so is the total cost of conglomeration in the low conglomeration equilibrium. Using the expression for $\Delta c$ and after some algebraic simplification:

$$
\begin{gathered}
\Pi(\underline{c})-\Pi(\bar{c})=[(\bar{\omega}+\Delta \omega) x(\bar{\omega}+\Delta \omega)-\bar{\omega} x(\bar{\omega})]-\Delta \omega Y_{M}+ \\
p_{H}\left(Y_{H}-Y_{M}\right)\left(1-c\left(1-p_{H}\right)\right)
\end{gathered}
$$

This expression evaluated at $\Delta \omega=0$ is $p_{H}\left(Y_{H}-Y_{M}\right)\left(1-c\left(1-p_{H}\right)\right)>0$ and its derivative with respect to $\Delta \omega$ is $x(\bar{\omega}+\Delta \omega)+(\bar{\omega}+\Delta \omega) x^{\prime}(\bar{\omega}+\Delta \omega)-Y_{M}<0$ because the second term is negative and $Y_{M}>x(\bar{\omega}+\Delta \omega)$. Therefore, there is a level $\widehat{\Delta \omega}$ such that for all $x()$ with $\Delta \omega<\widehat{\Delta \omega}$ the low conglomeration equilibrium is better. 


\section{Figure 2}
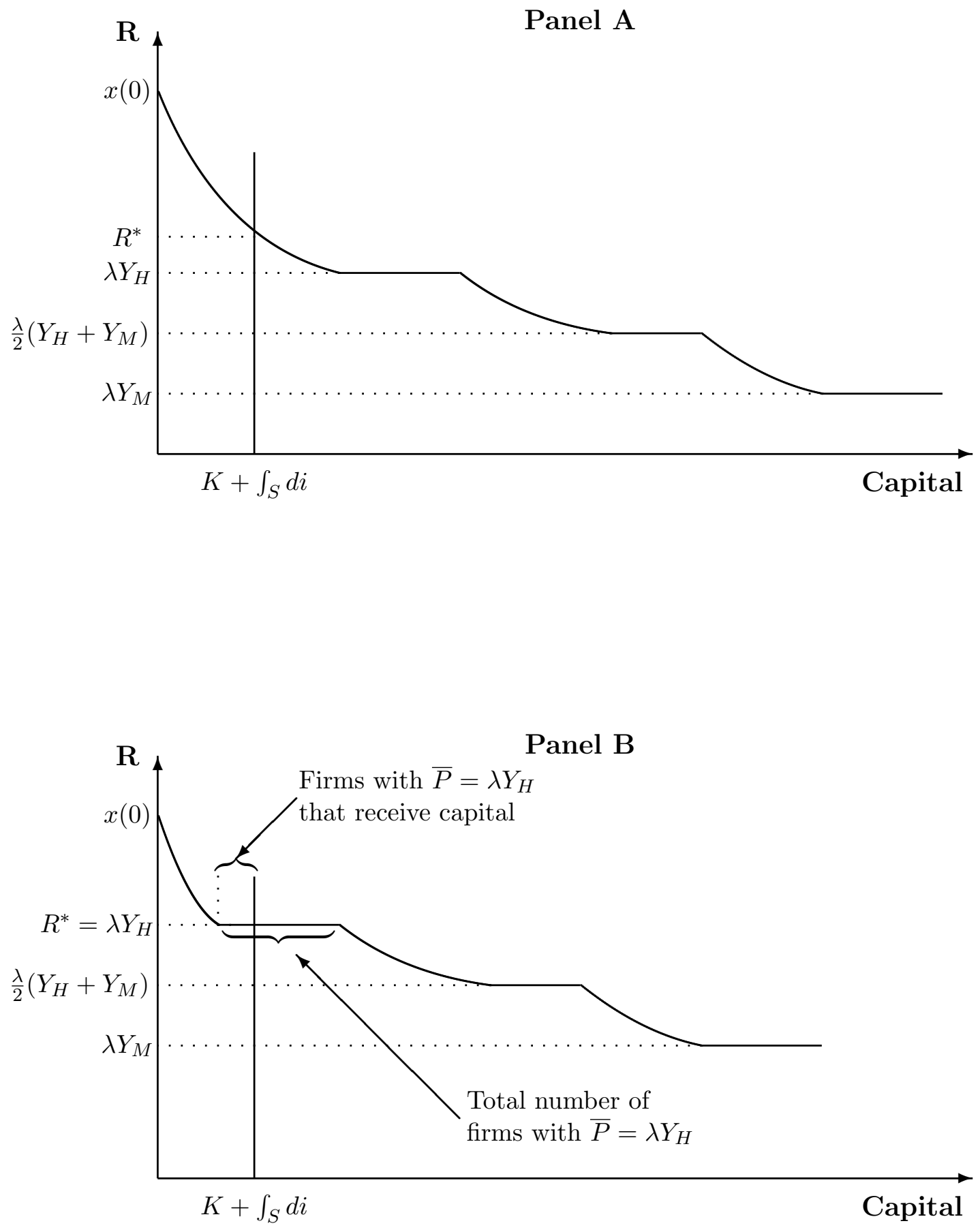


\section{Figure 3}
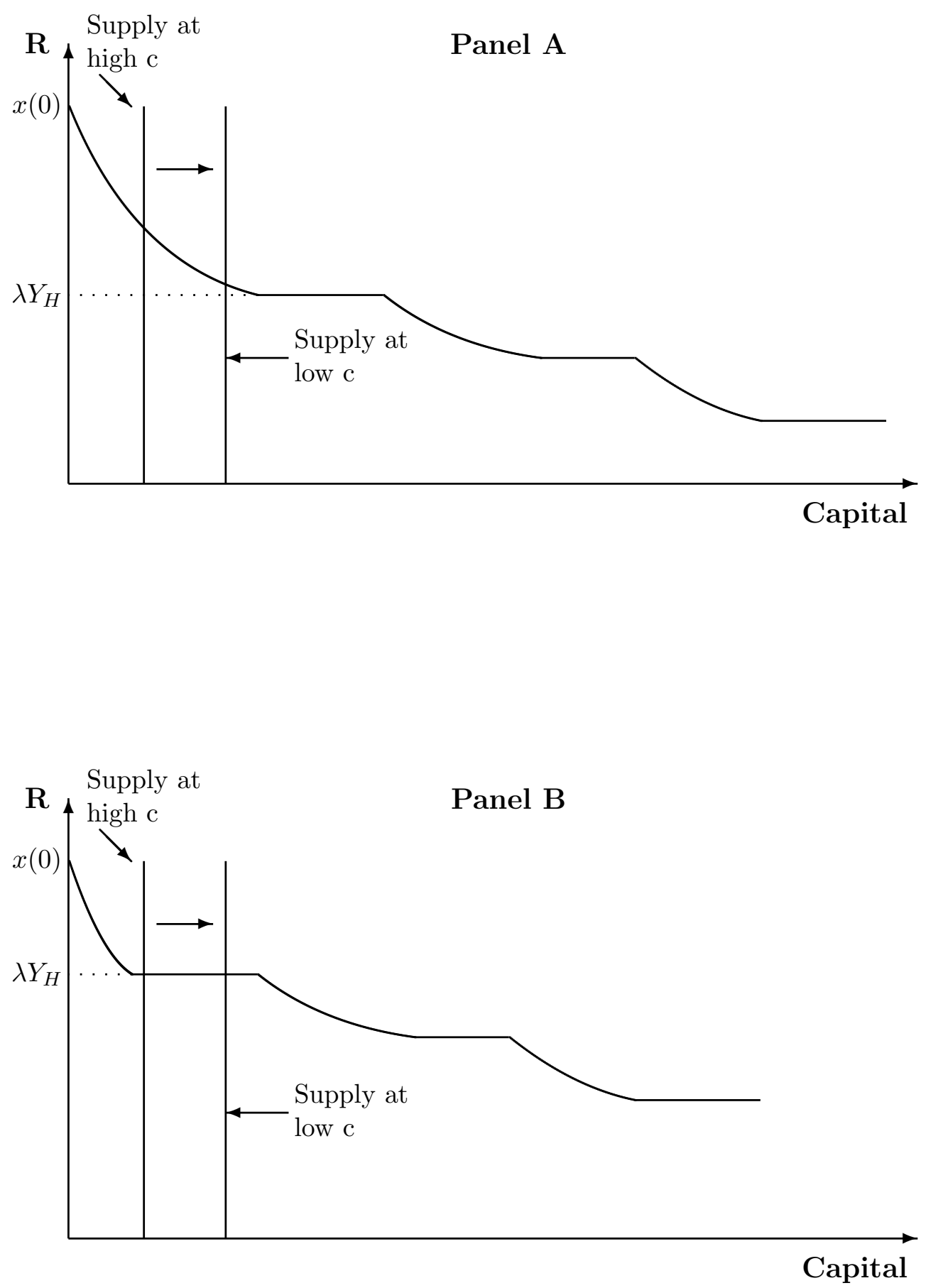


\section{Figure 4}
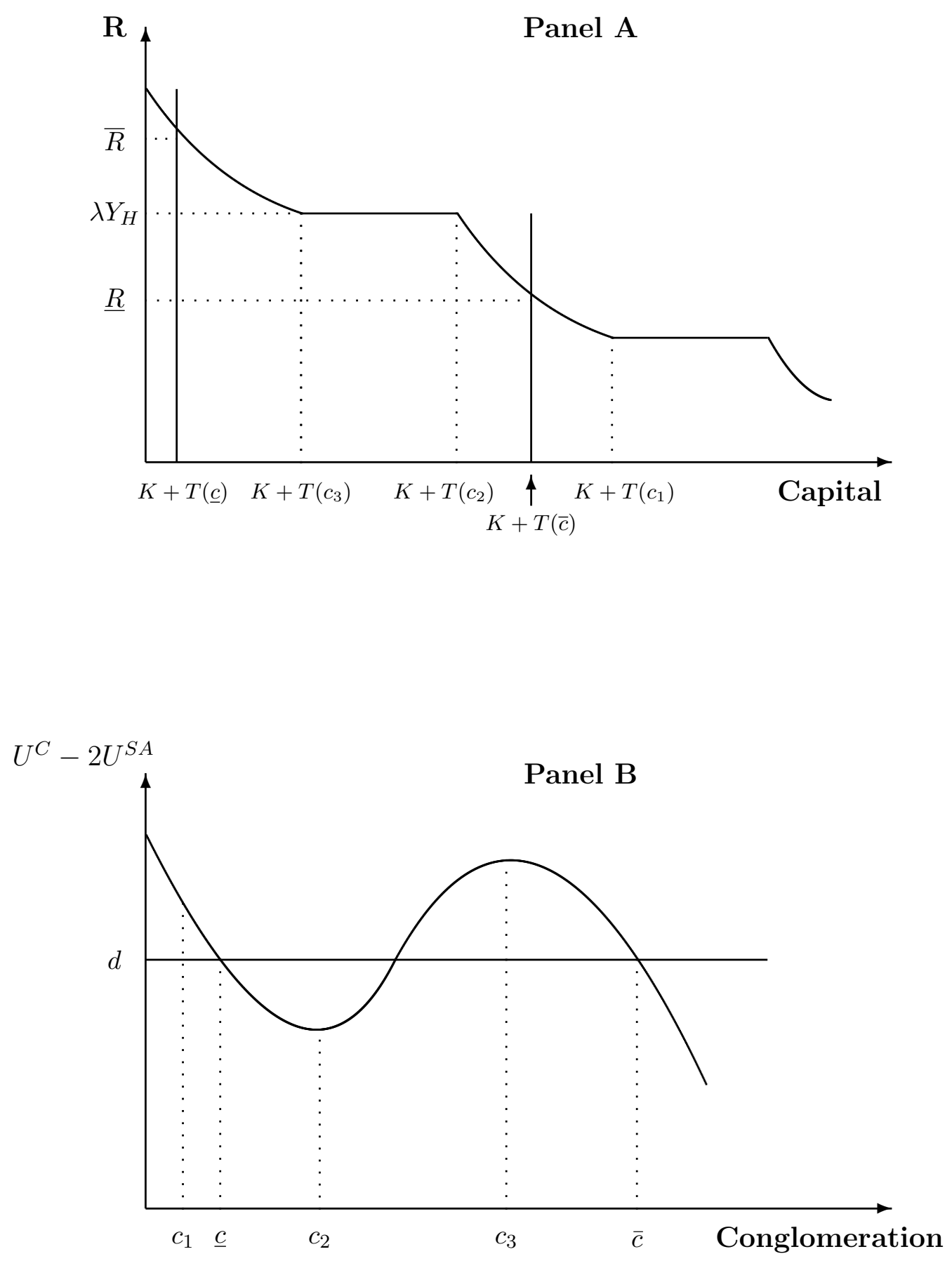